\title{
A generalised model for dynamic photocurrent responses at dye-sensitised liquid|liquid interfaces
}

\author{
Zdeněk Samec $^{\text {a }}$, Nicolas Eugster ${ }^{\text {b }}$, David J. Fermín ${ }^{\text {b,1 }}$, Hubert H. Girault ${ }^{\text {b,* }}$ \\ ${ }^{a}$ J. Heyrovský Institute of Physical Chemistry, Academy of Science of the Czech Republic, Dolejskova 3, CR-18223 Prague 8, Czech Republic \\ ${ }^{\mathrm{b}}$ Labarotoire d'Electrochimie Physique et Analytique, Institut de Chimie Moléculaire et Biologique, Ecole Polytechnique Fédérale de \\ Lausanne, CH-1015 Lausanne, Switzerland
}

Received 20 October 2004; accepted 15 December 2004

\begin{abstract}
The heterogeneous photoinduced electron transfer involving dyes adsorbed at the interface between two immiscible electrolyte solutions and redox molecules located in the adjacent phase manifests itself as photocurrent responses under potentiostatic conditions. Photocurrent transients as functions of the light intensity and bias potential allow the extraction of insightful information on the kinetics of the various processes associated with the photoinduced reaction. Previous analyses of this type of responses were based on phenomenological models that did not consider mass transport. In the present paper, we develop a generalised model for photocurrent transients taking into account the diffusion of reacting species to the interface. Comparison with the experimental data confirms that the responses can be described adequately by applying stationary conditions to the surface concentration of the photoactive species. Mechanistic aspects associated with the nature of the photocurrent relaxation on the microsecond time scale are examined. In particular, the dependence of the transient response on the light intensity indicates that charge recombination proceeds mainly as a first order reaction from an interfacial geminate ion pair. Coupled ion transfer reactions involving the photoproducts can also contribute to the photocurrent, depending on the formal ion transfer potential of the corresponding species.
\end{abstract}

(C) 2004 Elsevier B.V. All rights reserved.

Keywords: ITIES; Liquid interfaces; Photocurrent; Electron transfer

\section{Introduction}

Photoinduced heterogeneous electron transfer across liquid|liquid interfaces has been widely recognised as a model system for natural photosynthesis and heterogeneous photocatalysis [1-4]. One of the key aspects of photochemical reactions in these systems is that the efficiency of product separation can be enhanced by differences in solvation energy, diminishing the probability of back electron transfer processes. In a series

\footnotetext{
${ }^{*}$ Corresponding author. Tel.: +4 121693 3151; fax: +4 121693 3667.

E-mail address: hubert.girault@epfl.ch (H.H. Girault).

${ }^{1}$ Present address: Departement für Chemie und Biochemie, Universität Bern, Freiestrasse 3, CH-3012 Bern, Switzerland.
}

of papers by Kotov and Kuzmin [5-7], the effect of the polarisable liquid|liquid junction on the separation of photoproducts was studied by photocurrent measurements. The system studied featured the homogeneous generation of charged photoproducts, followed by the transfer of these species across the liquid|liquid boundary. The first measurements of photocurrent responses associated with heterogeneous photoinduced electron transfer were published by Marecek et al. [8] for the reduction of methylviologen in the aqueous phase by $\mathrm{Ru}(\mathrm{bpy})_{3}^{2+}$ in DCE or benzonitrile under chopped illumination. Although this work raised criticism due to the apparent absence of dc photocurrents under constant illumination [9], it opened the way to studies providing clear evidence of photoinduced electron transfer employing photocurrent measurements 
[10-14] or spectroscopic techniques [15-18]. During the last five years, efforts have been devoted to the exploration of fundamental aspects concerning the organisation and reactivity of photoactive species at the interface between two immiscible electrolyte solutions $[15,19,20]$. In these systems, the photoexcitation of dyes or semiconducting nanoparticles leads to heterogeneous charge transfer processes in the presence of redox couples located in the adjacent liquid phase $[9,12-14,18,21-27]$. These projects are relevant not only to theoretical aspects on electron transfer at molecular interfaces, but also to the development of new photoactive systems $[9,22,28,29]$. The photoreactivity of dyes is strongly linked to their specific adsorption at the liquid| liquid boundary. Various techniques ranging from surface second harmonic generation to photocurrent measurements have been used to probe the surface concentration and orientation of these species at the interface, as well as the formation of aggregates [24,25,30,31].

Recently, a series of papers based on photocurrent responses involving water soluble porphyrin species has addressed various aspects involved in the kinetics of photoinduced electron transfer across polarisable liquid| liquid junctions [12-14,18,21-27,32]. A general description of the heterogeneous photoreaction is shown in Fig. 1. The porphyrin dye $\mathrm{S}$ diffuses to the interface and undergoes heterogeneous photoreductive quenching by the donor $\mathrm{Q}$ in the organic phase. As discussed extensively in several publications, the sensitiser species $\mathrm{S}$ involved in the photoinduced heterogeneous electron transfer are specifically adsorbed at the liquid|liquid boundary $[12,21,24,32]$. This aspect has to be included in the estimations of the concentration profile of the active species.

Particular attention has been paid to the dependence of the rate constant of heterogeneous electron transfer on the thermodynamic driving force, employing series of ferrocene or quinone derivatives as redox species in the organic phase [26,27]. The driving force was varied by using quenchers of different redox potentials, as well as by tuning the Galvani potential difference between the two phases. The photocurrent responses as functions

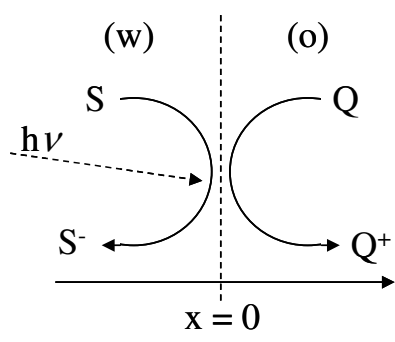

Fig. 1. Schematic representation of the photoinduced heterogeneous electron transfer reaction between a photoactive electron acceptor in the aqueous phase and an electron donor in the organic phase. of the Gibbs energy of electron transfer were rationalised in terms of Marcus-type behaviour of the phenomenological electron transfer rate constant, providing a reorganisation energy $\lambda$ of $1.05 \mathrm{eV}$ [26]. Within the framework of the Marcus model for a sharp liquid|liquid boundary, the magnitude of $\lambda$ yielded an average distance between the redox species of $0.8 \mathrm{~nm}$. Furthermore, the activationless limit of the bimolecular electron transfer rate constant was estimated to be $3 \times 10^{-19} \mathrm{~cm}^{4} \mathrm{~s}^{-1}$. All these parameters appear to indicate a strong nonadiabatic character of the electron transfer process.

These studies employed as photoactive species the heterodimer formed by the electrostatic association of oppositely charged metalloporphyrins. The negatively charged $\mathrm{Zn}(\mathrm{II}) \quad$ meso-tetrakis( $p$-sulphonatophenyl) porphyrin $\left(\mathrm{ZnTPPS}^{4-}\right)$ and the positively charged $\mathrm{Zn}$ (II) meso-tetrakis ( $N$-methylpyridyl) porphyrin $\left(\mathrm{ZnTMPyP}^{4+}\right)$ were reported to undergo spontaneous association with a rather large association constant $[20,21,27]$. The electrostatic attraction between the charged substituents and the hydrophobic interaction of the aromatic macrocycles cooperate in holding the individual species in close proximity such that extensive orbital overlap can occur [33-37]. The resulting ion pair, or heterodimer, features a strong affinity for the water|DCE interface [20]. While the photoexcitation of porphyrin monomers in the Q-band is usually followed by a relaxation to the triplet state in about $1 \mathrm{~ns}$, this complex features a fast relaxation to a charge-separated state of the form [(ZnTPPS $\left.)^{3-}(\mathrm{ZnTMPyP})^{3+}\right]$ [27]. This process occurs within less than $100 \mathrm{fs}$, much faster than the heterogeneous electron transfer reaction. Consequently, a competition is established between the decay of the triplet or charge-separated state and the heterogeneous electron transfer reaction, which takes place in the microsecond domain. The lifetime of the excited species is therefore a key parameter in the rationalisation of the magnitude of the photocurrent responses [32].

These photoinduced heterogeneous electron transfer reactions have so far been rationalised in terms of a phenomenological model where the analysis of photocurrent transients did not consider the kinetics of mass transport of the reacting species. The rationale behind this simplified approach was the linear dependence of the photocurrent on the photon flux at short times of illumination [26]. Furthermore, photocurrent transients in the presence of decamethylferrocene exhibit a quasisquare shape at low illumination levels, indicating that the photocurrent responses are controlled by the kinetics of heterogeneous electron transfer rather than mass transport phenomena $[21,26]$. However, this approach is not applicable to systems under strong illumination, where the quasi-steady state approximation is no longer valid. The dynamics of mass transport of reactants and products is expected to manifest itself not only by the absence of a steady-state photocurrent, but also by com- 
plex features in the intensity modulated photocurrent spectroscopy (IMPS) responses in the low frequency domain [14,23]. Consequently, a generalised model that considers the effect of mass transport on the photocurrent in the time and frequency domains is required to rationalise the behaviour at high photon fluxes.

The aim of the present work was to develop a model allowing a full characterisation of photocurrent responses at dye-sensitised liquid|liquid interfaces. Firstly, the effect of mass transport is analysed for the case of first order reactions (Section 3.1.2). We then address the problems of second order back electron transfer (Section 3.1.3) and coupled ion transfer (Section 3.1.4). Criteria for distinguishing between the various mechanisms proposed is provided by the dependence of the photocurrent relaxation on the light intensity in the cases of models B and C. Comparison of the simulations with experimental results is presented in Section 3.2. We also demonstrate that the analysis presented in $[26,27]$ gives a valid description of the dependence of the electron transfer rate constant $\left(k_{\mathrm{et}}^{\mathrm{II}}\right)$ on the thermodynamic driving force.

\section{Experimental}

All reagents employed in photocurrent measurements were analytical grade. The porphyrin salts $(\mathrm{Na})_{4} \mathrm{ZnTPPS}$ and $\mathrm{ZnTMPyP}(\text { tosylate })_{4}$ were purchased from Porphyrin Products, Inc. Bis(triphenyl-phosphoranylidene) ammonium tetrakis(pentafluorophenyl) borate (BTPPATPFB) and $\mathrm{Li}_{2} \mathrm{SO}_{4}$ were employed as the organic and aqueous phase supporting electrolytes, respectively. The preparation of BTPPATPFB has been reported elsewhere [14]. Measurements were carried out in a three-compartment glass cell provided with two platinum counter-electrodes and two Luggin capillaries for the reference electrodes. The geometrical surface area was $1.53 \mathrm{~cm}^{2}$. The electrochemical cell is presented in Fig. 4. The water|1,2-dichloroethane (DCE) junction was polarised via a custom-built four-electrode potentiostat, and the potential scale was corrected by the formal transfer potential of the cation tetramethylammonium $\left(\Delta_{\mathrm{o}}^{\mathrm{w}} \phi_{\mathrm{TMA}^{+}}^{\mathrm{o}^{\prime}}=0.160 \mathrm{mV}\right)$ [38]. The liquid|liquid junction was illuminated with the $442 \mathrm{~nm}$ line of an Omnichrome 2074-M-A03 He-Cd laser, employing a fast optical shutter.

\section{Results and discussion}

\subsection{Theory for the generalised model}

\subsubsection{Mechanism and general considerations}

The mechanism of the heterogeneous photoreaction depicted by Fig. 1 involves a series of first and second order competing reactions, as illustrated schematically in Fig. 2. The symbols $k_{\text {ads }}$ and $k_{\text {des }}$ represent the rate constants of adsorption and desorption of the photoactive species. Previous studies based on potential modulated fluorescence have shown that the adsorption rate constant of ZnTMPyP is of the order of $10^{9}$ $\mathrm{mol}^{-1} \mathrm{~cm}^{3} \mathrm{~s}^{-1}$, a value 4 orders of magnitude smaller than the diffusional limit [39]. The rate constant $k_{\mathrm{d}}$ is associated with the decay of the excited state, and $k_{\text {et }}^{\text {II }}$ is the bimolecular rate constant of electron transfer. $k_{\mathrm{b}}$ and $k_{\mathrm{ps}}$ are associated with back electron transfer and product separation steps. According to the mechanism in Fig. 2, a first competition takes place upon illumination between the decay of the excited state $\left(k_{\mathrm{d}}\right)$ and the photoinduced electron transfer step $\left(k_{\text {et }}^{\mathrm{II}}\right)$. A second competition is introduced when the products of the electron transfer reaction can either recombine to the starting reactants $\left(k_{\mathrm{b}}\right)$, or separate and diffuse to their respective phases $\left(k_{\mathrm{ps}}\right)$. As mentioned previously, the dynamics of the photoinduced electron transfer process have been thoroughly investigated in the case of the heterodimer ZnTPPS-ZnTMPyP. The analysis was based on the idea that back charge transfer and product separation processes, as well as diffusion effects, occur on a time scale which is orders of magnitude larger than the time constants of the forward electron transfer (taken as a pseudo-first order reaction with respect to $\mathrm{S}^{*}$ ) and relaxation of the excited state processes $\left(k_{\mathrm{et}}, k_{\mathrm{d}} \gg k_{\mathrm{b}}, k_{\mathrm{ps}}\right)[26,27]$. Consequently, variations in the initial values of the photocurrent observed upon illumination of the interface could be attributed to changes in the rate constant $k_{\mathrm{et}}^{\mathrm{II}}$. Under low illumination levels, the photocurrent relaxation observed on the ms time scale approaches a first order decay. It was therefore postulated that back electron transfer involves an interfacial ion-pair. However, it can also be conceived that back electron transfer takes place

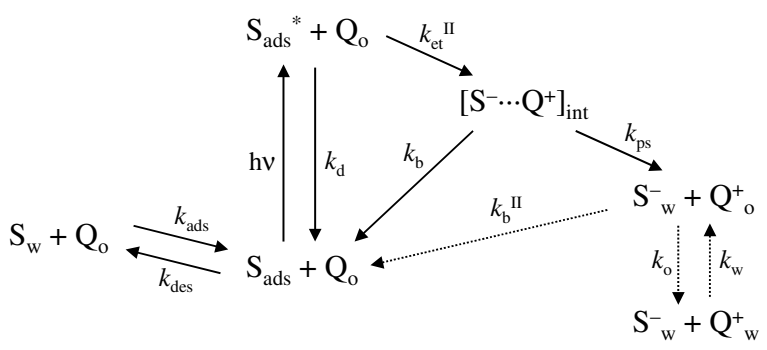

Fig. 2. Schematic representation of the photoinduced heterogeneous electron transfer reaction between a photoactive electron acceptor in the aqueous phase $(\mathrm{S})$ and an electron donor in the organic phase $(\mathrm{Q})$. Alternative reaction pathways are represented as dashed arrows. $k_{\text {ads }}$ and $k_{\mathrm{des}}$ represent the rate constants related to the adsorption and desorption of the photoactive species, $k_{\mathrm{d}}$ is the rate constant associated with the decay of the excited state, and $k_{\mathrm{et}}^{\mathrm{II}}$ is the bimolecular rate constant of electron transfer. $k_{\mathrm{b}}$ and $k_{\mathrm{ps}}$ are associated with back electron transfer and product separation steps. $k_{\mathrm{b}}^{\mathrm{II}}$ is related to a hypothetical second order recombination. $k_{\mathrm{o}}$ and $k_{\mathrm{w}}$ denote the rate constants associated with the ion transfer of the photoproduct $\mathrm{Q}^{+}$. 
as a second order process from the products of the photoreaction $\left(k_{\mathrm{b}}^{\mathrm{II}}\right)$. In addition, the photogenerated ion in the organic phase can be involved in partition equilibrium at the liquid|liquid boundary. Coupled ion transfer reactions $\left(k_{\mathrm{o}}\right)$ can also induce a photocurrent relaxation determined by the interfacial concentration of the photoproducts.

Following the classical approach developed for redox reactions at electrode surfaces, the current density $j$ can be generally related to the fluxes $J_{i}$ of charged species on one or the other side of the interface through

$j=\sum_{i} z_{i} F J_{i}^{\mathrm{w}}=\sum_{i} z_{i} F J_{i}^{\mathrm{o}}$.

The mechanism in Fig. 2 postulates the formation of an interfacial complex $\left[\mathrm{S}^{-} \cdots \mathrm{Q}^{+}\right]_{\mathrm{ads}}$ equivalent to the geminate ion-pair familiar from classical bulk photoelectrochemistry. This process largely determines the shape of the photocurrent response on the $\mu$ s time scale [14]. In order to describe the system accurately, we need to define how photo-generated charges are arranged at the liquid|liquid boundary. For the purpose of modelling, we shall assume that the charge of the geminate ion pair is split between the two phases as illustrated by Fig. 3. In this case, the forward $\left(k_{\mathrm{et}}^{\mathrm{II}}\right)$ and back electron transfer reactions involve the transfer of electrons across the interface and hence generate current. The electroneutrality condition then allows the surface charge densities on the aqueous $\left(q^{\mathrm{w}}\right)$ and organic $\left(q^{\mathrm{o}}\right)$ sides of the interface to be defined as

$$
\begin{aligned}
q^{\mathrm{w}} & =\sum_{i} z_{i} F \Gamma_{i}^{\mathrm{w}} \\
& =F \Gamma_{\mathrm{R}^{+}}^{\mathrm{w}}-F \Gamma_{\mathrm{X}^{-}}^{\mathrm{w}}+z_{\mathrm{S}} F\left(\Gamma_{\mathrm{S}}^{\mathrm{w}}+\Gamma_{\mathrm{S}^{*}}^{\mathrm{w}}\right)+z_{\mathrm{S}^{-}} F \Gamma_{\mathrm{SQ}} \\
& =-q^{\mathrm{o}}=-F \Gamma_{\mathrm{T}^{+}}^{\mathrm{o}}+F \Gamma_{\mathrm{Y}^{-}}^{\mathrm{w}}-z_{\mathrm{Q}^{+}} F \Gamma_{\mathrm{SQ}},
\end{aligned}
$$

where RX and TY denote the supporting electrolytes in the aqueous and organic phase, respectively.

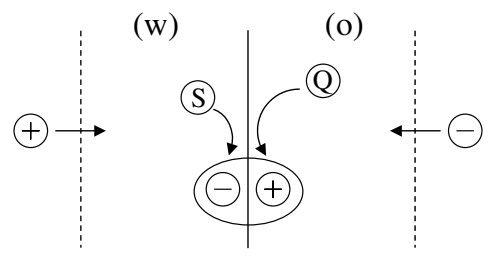

Fig. 3. Schematic representation of the additional surface charge generated by the formation of the geminate ion pair.

\subsubsection{Model $A$ - first order back electron transfer}

Model A assumes that back electron transfer reactions occur only from the interfacial complex, and that no ion transfer is involved (full arrows in Fig. 2). This mechanism can be described in terms of the following set of reactions [14,21,26,27]:

Adsorption and desorption of the photoactive species:

$\mathrm{S}_{\mathrm{w}} \underset{k_{\mathrm{des}}}{\stackrel{k_{\mathrm{ads}}}{\rightleftarrows}} \mathrm{S}_{\mathrm{ads}}$

Excitation and relaxation of the photoactive species:

$\mathrm{S}_{\mathrm{ads}} \underset{k_{\mathrm{d}}}{\stackrel{h v}{\rightleftarrows}} \mathrm{S}_{\mathrm{ads}}^{*}$

Heterogeneous electron transfer:

$\mathrm{S}_{\mathrm{ads}}^{*}+\mathrm{Q}_{\mathrm{o}} \stackrel{k_{\text {et }}^{\mathrm{II}}}{\rightarrow}\left[\mathrm{S}^{-} \cdots \mathrm{Q}^{+}\right]_{\mathrm{ads}}$

Back electron transfer:

$\left[\mathrm{S}^{-} \cdots \mathrm{Q}^{+}\right]_{\mathrm{ads}} \stackrel{k_{\mathrm{b}}}{\rightarrow} \mathrm{S}_{\mathrm{ads}}+\mathrm{Q}_{\mathrm{o}}$

Separation of the products:

$\left[\mathrm{S}^{-} \cdots \mathrm{Q}^{+}\right]_{\mathrm{ads}} \stackrel{k_{\mathrm{ps}}}{\longrightarrow} \mathrm{Q}_{\mathrm{o}}^{+}+\mathrm{S}_{\mathrm{w}}^{-}$

$\mathrm{S}$ denotes the photoactive species (sensitiser) in the aqueous phase, while $\mathrm{Q}$ represents the quencher in the organic phase. $\mathrm{S}^{*}$ is the acceptor in the photoexcited state. The bulk concentrations of $\mathrm{Q}^{+}$and $\mathrm{S}^{-}$are equal to zero. The bulk concentration of $\mathrm{Q}$ is $c_{\mathrm{Q}}^{\mathrm{o}}$. The supporting electrolytes RX and TY are present in the aqueous (w) and organic (o) phases, respectively. The charge transfer rate constants $k_{\text {et }}^{\mathrm{II}}$ and $k_{\mathrm{b}}$ are functions of the Galvani potential difference between the two liquids.

In the following development we shall consider the liquid|liquid interface as a sharp boundary located at $x=0$. The fluxes $J_{i}$ of the various electroactive species in Fig. 2 at this position are described in Appendix A. The changes in surface concentrations of the photoactive species can be expressed as

$\frac{\mathrm{d} \Gamma_{\mathrm{S}}}{\mathrm{d} t}=k_{\mathrm{ads}} c_{\mathrm{S}}^{\mathrm{w}}(0, t)-k_{\mathrm{des}} \Gamma_{\mathrm{S}}+k_{\mathrm{d}} \Gamma_{\mathrm{S}^{*}}-\sigma_{\mathrm{S}} \Phi \Gamma_{\mathrm{S}}+v_{\mathrm{b}}$,

$\frac{\mathrm{d} \Gamma_{\mathrm{S}^{*}}}{\mathrm{~d} t}=\sigma_{\mathrm{S}} \Phi \Gamma_{\mathrm{S}}-k_{\mathrm{d}} \Gamma_{\mathrm{S}^{*}}-v_{\mathrm{et}}$,

$\frac{\mathrm{d} \Gamma_{\mathrm{SQ}}}{\mathrm{d} t}=v_{\mathrm{et}}-v_{\mathrm{b}}-k_{\mathrm{ps}} \Gamma_{\mathrm{SQ}}$,

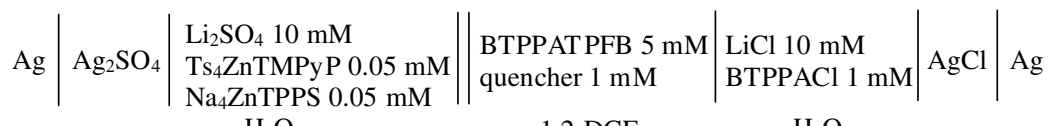

$$
\begin{aligned}
& \mathrm{H}_{2} \mathrm{O} \\
& \text { 1,2-DCE } \quad \mathrm{H}_{2} \mathrm{O}
\end{aligned}
$$

Fig. 4. Schematic representation of the electrochemical cell employed for photocurrent measurements. The concentration and nature of the quencher in the DCE phase are specified with the corresponding photocurrent data. 
where $\sigma_{\mathrm{S}}$ is the light capture cross-section of the adsorbed photoactive species and $\Phi$ is the photon flux across the interface. The terms $c_{i}$ and $\Gamma_{i}$ denote the volume and surface concentrations, respectively, and the index SQ refers to the interfacial complex $\left[\mathrm{S}^{-} \ldots \mathrm{Q}^{+}\right]_{\mathrm{ads}}$. The rates of electron transfer and back electron transfer are defined as

$v_{\text {et }}=k_{\mathrm{et}}^{\mathrm{II}} \Gamma_{\mathrm{S}^{*}} c_{\mathrm{Q}}^{\mathrm{o}}(0, t)$

and

$v_{\mathrm{b}}=k_{\mathrm{b}} \Gamma_{\mathrm{SQ}}$.

As described by Eq. (1), the electric current density is obtained by summation of the fluxes on the aqueous side of the interface (see Appendix A). The following expression is obtained:

$j_{\mathrm{ph}}=\sum_{i} z_{i} F J_{i}=F\left(v_{\mathrm{et}}-v_{\mathrm{b}}\right)+\frac{\mathrm{d} q^{\mathrm{w}}}{\mathrm{d} t}$.

In order to solve the transient current density during a light step perturbation, a variety of considerations should be taken into account. Effectively, the potential drop across the liquid|liquid boundary remains constant during the illumination. Impedance measurements employing an ideal resistance element show that the phase shift associated with the operational amplifiers of the potentiostat occurs at frequencies above $5 \mathrm{kHz}$. This value is considerably higher than the $R C$ constant of the cell. On the other hand, the response time of the optical shutter is on the $\mu$ s time scale; hence $\Phi$ can be effectively taken as a step function. Finally, it is assumed that the changes in the bulk and surface concentrations of all species involved in Fig. 2 are small enough to allow for an expansion of the electric current density in terms of a Taylor series.

In the absence of back electron transfer, it has been shown that photocurrent responses below $10^{-5} \mathrm{~A} \mathrm{~cm}^{-2}$ exhibit a linear dependence on the photon flux [26]. This behaviour implies that the surface concentration of the photoactive species can be taken as a constant, i.e. $\mathrm{d} \Gamma_{\mathrm{S}} / \mathrm{d} t=0$, during the time scale of the measurement. Based on this experimental fact, we shall exclude changes in the surface concentration of $S$ as a first approximation. The analysis of the photocurrent transients performed in Section 3.2 demonstrates that this approximation is self-consistent over a wide range of light intensities. Considering that the adsorptiondesorption equilibrium of porphyrins exhibits finite rate constants [39], it can be postulated that the stationary surface concentration results from the regeneration of the ground state by redox processes (e.g. oxygen reduction by $\mathrm{S}^{-}$). However, the present model for transient responses can still be fully developed without explicitly invoking the nature of the porphyrin regeneration. The solution for $\Gamma_{\mathrm{S}^{*}}$ can be obtained from applying a Laplace transform to Eq. (9):

$s \overline{\Delta \Gamma_{\mathrm{S}^{*}}}=\frac{\sigma_{\mathrm{S}} \Phi \Gamma_{\mathrm{S}}}{s}-\left(k_{\mathrm{d}}+k_{\mathrm{et}}^{\mathrm{II}} c_{\mathrm{Q}}^{\mathrm{o}}\right) \overline{\Delta \Gamma_{\mathrm{S}^{*}}}-k_{\mathrm{et}}^{\mathrm{II}} \Gamma_{\mathrm{S}^{*}}^{0} \overline{\Delta c_{\mathrm{Q}}^{\mathrm{o}}}$

where $c_{\mathrm{Q}}^{\mathrm{o}}$ is the bulk concentration of quencher (as well as the initial concentration in the vicinity of the interface), and $\Delta c_{\mathrm{Q}}^{\mathrm{O}}$ is related to the change in concentration of $\mathrm{Q}$ at the interface. Considering that the initial surface concentration of excited state $\Gamma_{\mathrm{S}^{*}}^{0}$ is equal to zero, the evolution of $\Gamma_{\mathrm{S}^{*}}$ in the time domain can be described as

$\Gamma_{\mathrm{S}^{*}}=\frac{\sigma_{\mathrm{S}} \Phi \Gamma_{\mathrm{S}}}{k_{\mathrm{et}}^{\mathrm{II}} c_{\mathrm{Q}}^{\mathrm{o}}+k_{\mathrm{d}}}\left(1-\mathrm{e}^{-\left(k_{\mathrm{et}}^{\mathrm{II}} c_{\mathrm{Q}}^{\mathrm{o}}+k_{\mathrm{d}}\right) t}\right)$.

Since the time constants associated with the decay of the excited state as well as the electron transfer event are much larger than the time scale of the photocurrent transient experiment $[20,26]$, it can be assumed that the surface concentration of $\mathrm{S}^{*}$ reaches a stationary value upon the step change $\Phi$ in the light flux:

$\Gamma_{\mathrm{S}^{*}}^{\mathrm{ss}}=\frac{\sigma_{\mathrm{S}} \Phi \Gamma_{\mathrm{S}}}{k_{\mathrm{d}}+k_{\mathrm{et}}^{\mathrm{II}} c_{\mathrm{Q}}^{\mathrm{c}}}$.

Based on these kinetic considerations, the following expression for the electric current density is obtained (see Appendix A):

$\overline{\Delta j_{\mathrm{ph}}}=F \frac{\left(s+k_{\mathrm{ps}}\right) g}{s\left(s+k_{\mathrm{b}}+k_{\mathrm{ps}}\right)+\left(k_{\mathrm{ps}}+s\right) \lambda_{\mathrm{et}} s^{\frac{1}{2}}}+s \overline{\Delta q^{\mathrm{w}}}$,

where

$g=k_{\mathrm{et}}^{\mathrm{II}} c_{\mathrm{Q}}^{\mathrm{o}} \Gamma_{\mathrm{S}^{*}}=\frac{k_{\mathrm{et}}^{\mathrm{II}} c_{\mathrm{Q}}^{\mathrm{o}}}{k_{\mathrm{et}}^{\mathrm{II}} c_{\mathrm{Q}}^{\mathrm{o}}+k_{\mathrm{d}}} \sigma_{\mathrm{S}} \Gamma_{\mathrm{S}} \Phi$,

$\lambda_{\mathrm{et}}=\frac{g}{\left(D_{\mathrm{Q}}^{\mathrm{o}}\right)^{\frac{1}{2}} c_{\mathrm{Q}}^{\mathrm{o}}}$.

The term $g$ corresponds to the flux of electron injection. Independent estimations of $\Gamma_{\mathrm{S}}$ from surface tension data [20] and rate constants from photocurrent measurement $[12,26,27]$ reveal that the flux of electron injection can be in the range of $10^{-12}-10^{-9} \mathrm{~mol} \mathrm{~s}^{-1} \mathrm{~cm}^{-2}$, depending on the applied potential and photon flux. Changes in the surface charge density can be written as

$$
\begin{aligned}
\overline{\Delta q^{\mathrm{w}}} & =\left(\frac{\partial q^{\mathrm{w}}}{\partial E}\right) \overline{\Delta E}+\left(\frac{\partial q^{\mathrm{w}}}{\partial\left(F z_{\mathrm{S}^{-}} \Gamma_{\mathrm{SQ}}\right)}\right) \overline{\Delta\left(F z_{\mathrm{S}^{-}} \Gamma_{\mathrm{SQ}}\right)} \\
& =-R C \overline{\Delta j_{\mathrm{ph}}}+p F z_{\mathrm{S}^{-}} \overline{\Delta \Gamma_{\mathrm{SQ}}} .
\end{aligned}
$$

The first term in Eq. (20) corresponds to the attenuation of the photocurrent responses by the $R C$ component of the cell. Indeed, the interfacial capacitance is the derivative of the charge with respect to the potential $\left(\partial q^{\mathrm{w}} / \partial E=C\right)$, and we have $\overline{\Delta E}=-R \overline{\Delta j_{\mathrm{ph}}}$. The second term arises from the changes in free charge with respect to the adsorbed charge. The parameter 
$p=\partial q^{\mathrm{W}} / \partial\left(F z_{\mathrm{S}^{-}} \Gamma_{\mathrm{SQ}}\right)$ is related to changes in the charge of the double layer due to the formation of the geminate ion pair at the liquid|liquid junction. The nature of $p$ is discussed further, later in the text. Combining Eqs. (17) and (20), the following expression is obtained for the electric current density:

$\overline{\Delta j_{\mathrm{ph}}}=\frac{F g}{1+R C s} \frac{k_{\mathrm{ps}}+s\left(1+z_{\mathrm{S}^{-}} p\right)}{\left(s+k_{\mathrm{b}}+k_{\mathrm{ps}}\right) s+\left(s+k_{\mathrm{ps}}\right) \lambda_{\mathrm{et}} s^{\frac{1}{s^{2}}}}$.

In the case of a modulation technique such as IMPS $[14,23,40]$, the response from the experiment is in the frequency domain and no inverse transformation is needed. The frequency dependent signal is obtained by replacing the Laplace variable $s$ by $\mathrm{i} \omega$. Hence, the transfer function of the cell can be written as

$$
\begin{aligned}
T & =\frac{\overline{\Delta j_{\mathrm{ph}}}}{F \overline{\Delta \Phi}} \\
& =\frac{\frac{g}{\Phi_{0}}}{1+R C i \omega}\left(\frac{k_{\mathrm{ps}}+\mathrm{i} \omega\left(1+z_{\mathrm{S}^{-}} p\right)}{i \omega+k_{\mathrm{ps}}+k_{\mathrm{b}}+\left(\mathrm{i} \omega+k_{\mathrm{ps}}\right) \lambda_{\mathrm{et}}(i \omega)^{-\frac{1}{2}}}\right),
\end{aligned}
$$

where $\omega$ is the angular frequency of the sinusoidal illumination. The parameter $\Phi_{0}$ corresponds to the dc photon flux, while $\Delta \Phi$ is related to the amplitude of the modulation. The IMPS technique allows resolution of the contributions from the various time constants associated with the back charge transfer processes-product separation competition, coupled ion transfer and $R C$ attenuation of the cell $[14,23]$. It should also be mentioned that, in the case where $p$ and the diffusion parameter $\lambda_{\text {et }}$ tend to zero, Eq. (22) simplifies to the phenomenological expression described in previous work [14,23]. This limiting case arises when the diffusion flux of the quencher to the surface is larger than the flux of electron injection $g$.

The time dependent photocurrent is obtained from the inverse Laplace transform of Eq. (21), which does not yield an analytical expression. A numeric method must be applied to obtain theoretical photocurrent transients for the general case. On the other hand, an analytical solution is available under low photon fluxes, where the effect of diffusion is minimised (i.e. $\lambda_{\text {et }} \sim 0$ ). Neglecting the RC component, Eq. (21) simplifies to

$\overline{\Delta j_{\mathrm{ph}}}=F g \frac{k_{\mathrm{ps}}+s\left(1+z_{\mathrm{S}^{-}} p\right)}{\left(s+k_{\mathrm{ps}}+k_{\mathrm{b}}\right) s}$.

Considering as a first approximation that the parameter $p$ is equal to zero, this expression yields in the time domain

$j_{\mathrm{ph}}=F g\left(\frac{k_{\mathrm{ps}}}{k_{\mathrm{ps}}+k_{\mathrm{b}}}+\frac{k_{\mathrm{b}}}{k_{\mathrm{ps}}+k_{\mathrm{b}}} \mathrm{e}^{-\left(k_{\mathrm{ps}}+k_{\mathrm{b}}\right) t}\right)$.

The two limiting cases of Eq. (24) are easily obtained. At very short illumination times, the photocurrent is described by the flux of electron injection multiplied by Faraday's constant. The steady-state photocurrent is given by

$$
\begin{aligned}
j_{\mathrm{ph}}^{\mathrm{ss}} & =F g \frac{k_{\mathrm{ps}}}{k_{\mathrm{ps}}+k_{\mathrm{b}}} \\
& =F \sigma_{\mathrm{S}} \Gamma_{\mathrm{S}} \Phi\left(\frac{k_{\mathrm{et}}^{\mathrm{II}} c_{\mathrm{Q}}^{\mathrm{o}}}{k_{\mathrm{et}}^{\mathrm{I}} c_{\mathrm{Q}}^{\mathrm{o}}+k_{\mathrm{d}}}\right)\left(\frac{k_{\mathrm{ps}}}{k_{\mathrm{ps}}+k_{\mathrm{b}}}\right) .
\end{aligned}
$$

Fig. 5 demonstrates the predicted effect of the rate $k_{\mathrm{b}}$ on the photocurrent response. The steady state current is determined by the competition between the product separation and back electron transfer reactions, while the initial current corresponds to the product $F g$ in Eq. (24) and depends on the rates of decay of the excited state and forward electron transfer. Eq. (25) is consistent with the phenomenological expression employed for estimating $k_{\mathrm{et}}^{\mathrm{II}}$ from photocurrent responses in previous work [12,26,27].

The forward electron transfer reaction in Fig. 2 involves the creation of adsorbed charged species at the interface. In order to maintain electroneutrality, an ion of opposite charge should enter the diffuse layer, as illustrated in Fig. 3. However, the relation between changes in the adsorbed charge and the free charge in the diffuse layer is not straightforward, as the formation of ion pairs modifies the potential distribution at the interface. The problem can be simplified by assuming a linear relationship between the free and adsorbed charges $\left(q_{\mathrm{free}}^{\mathrm{W}}\right.$ and $q_{\mathrm{ads}}^{\mathrm{w}}$, respectively) in the parameter $p$ :

$$
\begin{aligned}
p & =\frac{\partial q^{\mathrm{w}}}{\partial\left(z_{\mathrm{S}^{-}} F \Gamma_{\mathrm{SQ}}\right)}=1+\frac{\partial\left(F \Gamma_{\mathrm{R}^{+}}^{\mathrm{w}}+F \Gamma_{\mathrm{X}^{-}}^{\mathrm{w}}\right)}{\partial\left(z_{\mathrm{S}^{-}} F \Gamma_{\mathrm{SQ}}\right)} \\
& =1+\frac{\partial q_{\mathrm{free}}^{\mathrm{w}}}{\partial q_{\mathrm{ads}}^{\mathrm{w}}} .
\end{aligned}
$$

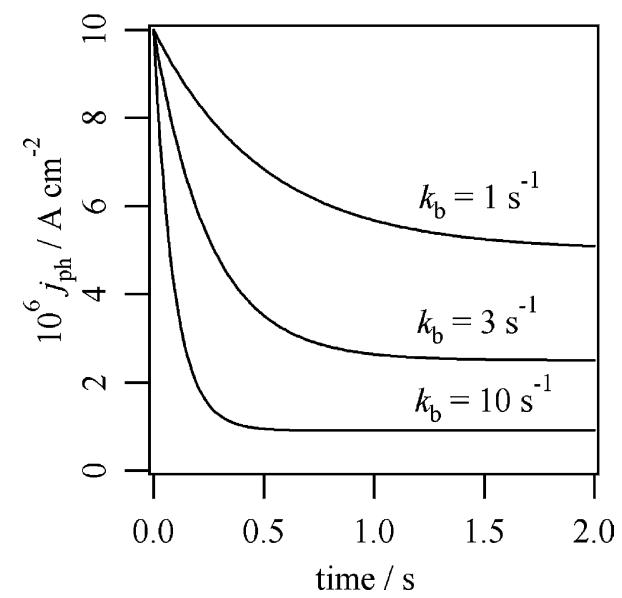

Fig. 5. Simulated photocurrent transients for various rates of back electron transfer, calculated from Eq. (24) with $g=10^{-10} \mathrm{~mol} \mathrm{~s}^{-1} \mathrm{~cm}^{-2}$, $k_{\mathrm{ps}}=1 \mathrm{~s}^{-1}, p=0$ and $k_{\mathrm{b}}$ as indicated in the graph. 
An intuitive situation would be that the additional charge at the interface is immediately balanced. In this case $\partial q_{\text {free }}^{\mathrm{w}} / \partial q_{\mathrm{ads}}^{\mathrm{w}}=-1$, and $p=0$. This situation appears to be supported by the experimental data, and will be considered in all simulations unless specified otherwise. The other limiting case arises when the free excess charge is not affected by the change in adsorbed charge, hence $\partial q_{\mathrm{free}}^{\mathrm{w}} / \partial q_{\mathrm{ads}}^{\mathrm{w}}=0$ and $p=1$. Fig. 6 shows the effect of $p$ on the photocurrent transients calculated from Eq. (24). The effect of this parameter can be difficult to separate from that of the back electron transfer reaction in the case of $p$ values comprised between 0 and 0.6 . The response corresponding to $p>0.6$ was not observed experimentally.

Although Eq. (21) cannot be transformed analytically into the time domain, the method developed by Stehfest $[41,42]$ can be used for numerical simulation of the photocurrent transients. The algorithm described in Appendix D has been tested on the simplified equation (24), and very good correlation was observed between the numerical and analytical inversions. Fig. 7(a) illustrates the effect of the diffusion coefficient of the quencher on the photocurrent transient response. From cyclic voltammetry on a Pt microelectrode, the diffusion coefficient of ferrocene in DCE can be estimated as $1.4 \times 10^{-5} \mathrm{~cm}^{2} \mathrm{~s}^{-1}$. The important information provided by these simulations is that the initial photocurrent is not affected by the depletion of quencher at the interface. This result consolidates the analysis of the dependence of $k_{\mathrm{et}}^{\mathrm{II}}$ on the driving force associated with the electron transfer process based on the initial photocurrent values presented in [26]. On the other hand, the charging of the double layers introduces a delay in the photocurrent rise, as illustrated by Fig. 7(b). The initial photocurrent is attenuated depending on the value of the $R C$ constant of the cell. These results confirm that

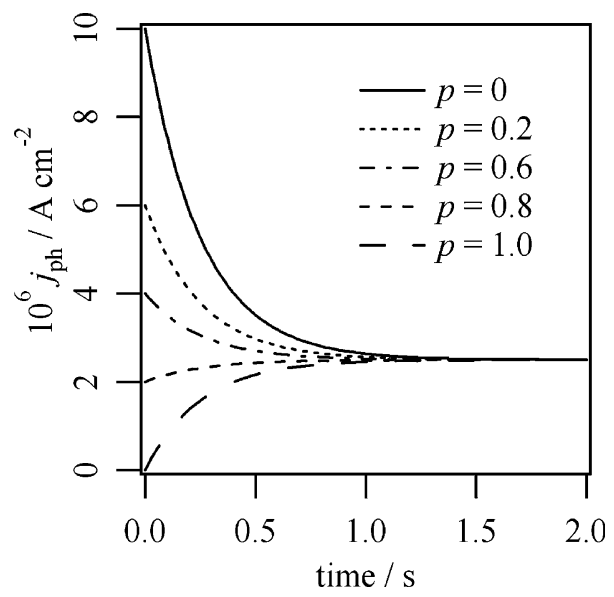

Fig. 6. Simulated photocurrent transients for various values of $p$, calculated from Eq. (24) with $g=10^{-10} \mathrm{~mol} \mathrm{~s}^{-1} \mathrm{~cm}^{-2}, k_{\mathrm{ps}}=1 \mathrm{~s}^{-1}$, $k_{\mathrm{b}}=3 \mathrm{~s}^{-1}$ and $p$ as indicated in the graph.
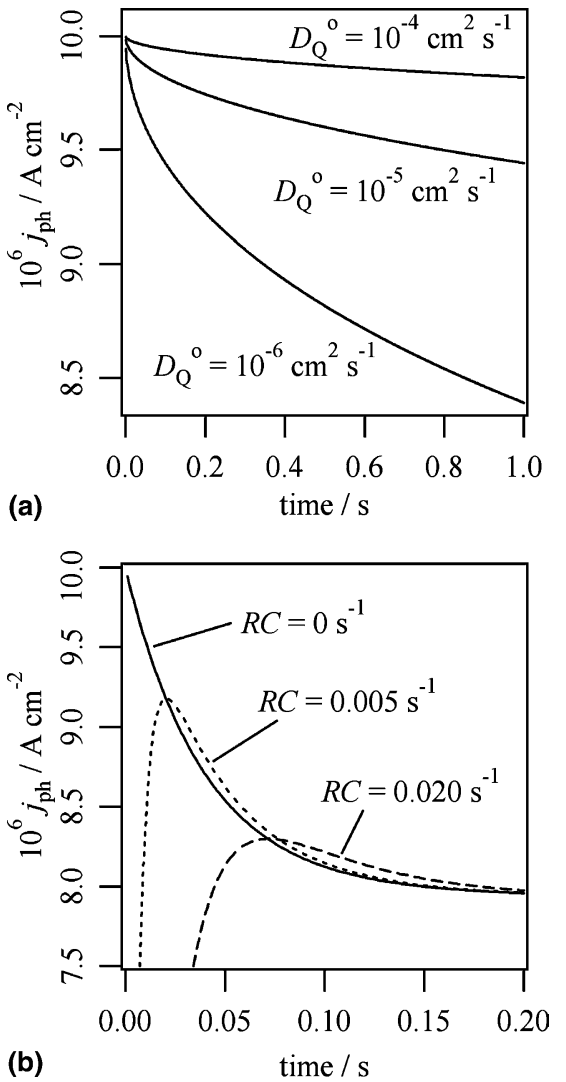

Fig. 7. Effect of the diffusion coefficient on the simulated photocurrent responses (model $\mathrm{A}$ ) in the absence of $R C$ attenuation and back charge transfer (a). Calculated from Eq. (21) with the parameters $g=10^{-10} \mathrm{~mol} \mathrm{~s}^{-1} \mathrm{~cm}^{-2}, c_{\mathrm{Q}}^{\mathrm{o}}=10^{-3} \mathrm{~mol} \mathrm{dm}^{-3}, k_{\mathrm{ps}}=20 \mathrm{~s}^{-1}$ and $D_{\mathrm{Q}}^{\mathrm{o}}$ as indicated in the graph. Simulated photocurrent responses (model A) for various values of the $R C$ constant (b). Calculated from Eq. (21) with the parameters in (a), as well as $k_{\mathrm{b}}=4 \mathrm{~s}^{-1}, D_{\mathrm{Q}}^{\mathrm{o}}=10^{-5} \mathrm{~cm}^{2} \mathrm{~s}^{-1}$ and $R C$ as indicated in the graph.

in the presence of a strong relaxation due to back electron transfer, the effect of the $R C$ time constant must be deconvoluted from the photocurrent transient in order to obtain accurate estimations of the flux of electron injection.

\subsubsection{Model B - second order back electron transfer}

In the previous model, back charge transfer reactions were supposed to occur only from the interfacial complex formed upon electron transfer $\left(k_{\mathrm{b}}\right)$. However, a charge recombination reaction from the free photoproducts could be envisaged, as commonly observed in homogeneous photochemical processes. In the following scheme we consider the forward electron transfer step as leading directly to the photoproducts. Simulation of the effect of the bimolecular back charge transfer on the photocurrent transients at various light intensities should allow discrimination between first $\left(k_{\mathrm{b}}\right)$ and second order recombination $\left(k_{\mathrm{b}}^{\mathrm{II}}\right)$. The steps (5)-(7) in the reaction scheme for model $\mathrm{A}$ are replaced by the following processes: 
Electron transfer:

$\mathrm{S}_{\mathrm{ads}}^{*}+\mathrm{Q}_{\mathrm{o}} \stackrel{{ }_{\mathrm{et}}^{\mathrm{II}}}{\rightarrow} \mathrm{Q}_{\mathrm{o}}^{+}+\mathrm{S}_{\mathrm{ads}}^{-}$

Second order back electron transfer:

$\mathrm{Q}_{\mathrm{o}}^{+}+\mathrm{S}_{\mathrm{ads}}^{-} \stackrel{k_{\mathrm{b}}^{\mathrm{II}}}{\rightarrow} \mathrm{S}_{\mathrm{ads}}+\mathrm{Q}_{\mathrm{o}}$

Eqs. (27) and (28) describe a fundamentally different problem from that of model A, revealing important implications on how the photoinduced mechanism is conceived. In the case of model A, back electron transfer proceeds as a first order reaction from the interfacial ion-pair. In the present model, the photoproducts generated at the liquid|liquid boundary are allowed to react with free species within the interfacial region. Consequently, the back electron transfer follows a second order rate law, as expressed by Eq. (30). The assumption made in model A that the surface concentration of $\mathrm{S}$ is constant remains, and the steady-state surface concentration of $\mathrm{S}^{*}$ is still expressed by Eq. (15). The evolution of the surface concentration of $\mathrm{S}^{-}$is given by

$\frac{\mathrm{d} \Gamma_{\mathrm{S}^{-}}}{\mathrm{d} t}=v_{\mathrm{et}}-v_{\mathrm{b} 2}$,

where $v_{\text {et }}$ is expressed by Eq. (11) and

$v_{\mathrm{b} 2}=k_{\mathrm{b}}^{\mathrm{II}} \Gamma_{\mathrm{S}^{-}} c_{\mathrm{Q}^{+}}^{\mathrm{o}}(0, t)$.

Expression (29) implicitly assumes that the dynamics of regeneration of $\mathrm{S}_{\mathrm{ads}}$ do not affect the dynamics of second order back electron transfer. Obviously, this limiting condition is essential in order to elucidate whether step (28) plays any role in the photocurrent responses. The expressions for the fluxes of the supporting electrolytes remain as in the case of model $\mathrm{A}$. The photocurrent can be expressed as

$j_{\mathrm{ph}}=F\left(v_{\mathrm{et}}-v_{\mathrm{b} 2}\right)+\frac{\mathrm{d} q^{\mathrm{w}}}{\mathrm{d} t}$.

Owing to the two time-dependent parameters in Eq. (30) the transport problem is non-linear and cannot be solved using the same procedure as in model A. Nevertheless, the Laplace transform can be used to obtain the relationship between the concentrations changes and the faradaic photocurrent density (see Appendix B). Neglecting the effects of double layer charging, the photocurrent density can be written as

$j_{\mathrm{ph}}(t)=F g(1+\Delta x)-B \Delta x^{2}$,

where $g$ is expressed by Eq. (18) and

$B=F k_{\mathrm{b}}^{\mathrm{II}}\left(\frac{D_{\mathrm{Q}}^{\mathrm{o}}}{D_{\mathrm{S}^{-}}^{\mathrm{W}}}\right)^{\frac{1}{2}}\left(c_{\mathrm{Q}}^{\mathrm{o}}\right)^{2}$.

Eq. (32) introduces the dimensionless concentration change $\Delta x(t)$, which is related to $j_{\mathrm{ph}}$ through the convolution integral
$\Delta x(t)=\frac{\Delta c_{\mathrm{Q}}^{\mathrm{o}}}{c_{\mathrm{Q}}^{\mathrm{o}}}=-\frac{1}{F\left(\pi D_{\mathrm{Q}}^{\mathrm{o}}\right)^{\frac{1}{2}} c_{\mathrm{Q}}^{\mathrm{o}}} \int_{0}^{t} \frac{j_{\mathrm{ph}}(\tau)}{(t-\tau)^{\frac{1}{2}}} \mathrm{~d} \tau$.

In order to simulate the faradaic photocurrent it is necessary to solve Eq. (32) numerically. Fig. 8 shows the effect of the bimolecular rate of back electron transfer on the simulated photocurrent, as well as the corresponding relative changes in concentration.

Fig. 9 illustrates the effect of the light intensity on the normalised photocurrent responses obtained with model B. The shape of the responses exhibits drastic changes when the illumination intensity is varied over two decades. This phenomenon was not observed experimentally. Indeed, the rate of back electron transfer shows very little dependence on the light intensity, suggesting that the photocurrent relaxation arises mainly from first order recombination (see Section 3.2).

\subsubsection{Model C-coupled transfer of ionic photoproducts}

The photoinduced electron transfer reaction generates new species at the interface. Owing to their different charge, these photoproducts feature solvation properties
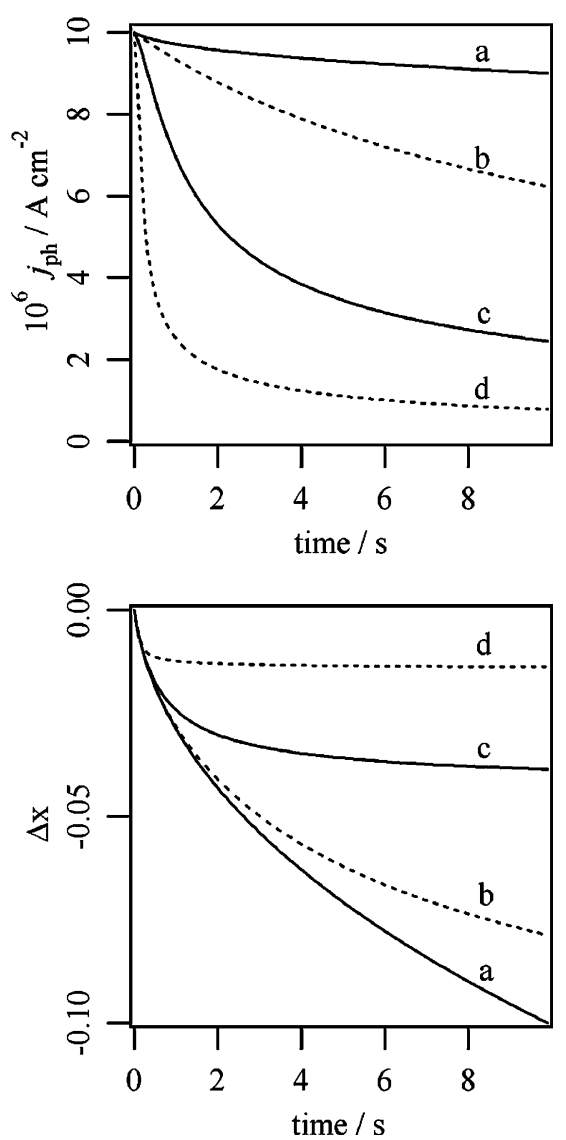

Fig. 8. Simulated photocurrent transients and corresponding dimensionless concentration change for second order back charge transfer (model B), calculated from Eq. (32) employing the parameters $g=10^{-10} \mathrm{~mol} \mathrm{~s}^{-1} \mathrm{~cm}^{-2}, c_{\mathrm{Q}}^{\mathrm{o}}=10^{-3} \mathrm{moldm}^{-3}, D_{\mathrm{O}^{+}}^{\mathrm{o}}=D_{\mathrm{S}^{-}}^{\mathrm{W}}=10^{-5} \mathrm{~cm}^{2} \mathrm{~s}^{-1}$ and $k_{\mathrm{b}}^{\mathrm{II}}=0(\mathrm{a}), k_{\mathrm{b}}^{\mathrm{II}}=0.05 \mathrm{dm}^{3} \mathrm{~mol}^{-1} \mathrm{~s}^{-1}$ (b), $k_{\mathrm{b}}^{\mathrm{II}}=0.5 \mathrm{dm}^{3} \mathrm{~mol}^{-1} \mathrm{~s}^{-1}$ (c), $k_{\mathrm{b}}^{\mathrm{II}}=5 \mathrm{dm}^{3} \mathrm{~mol}^{-1} \mathrm{~s}^{-1}$ (d). 


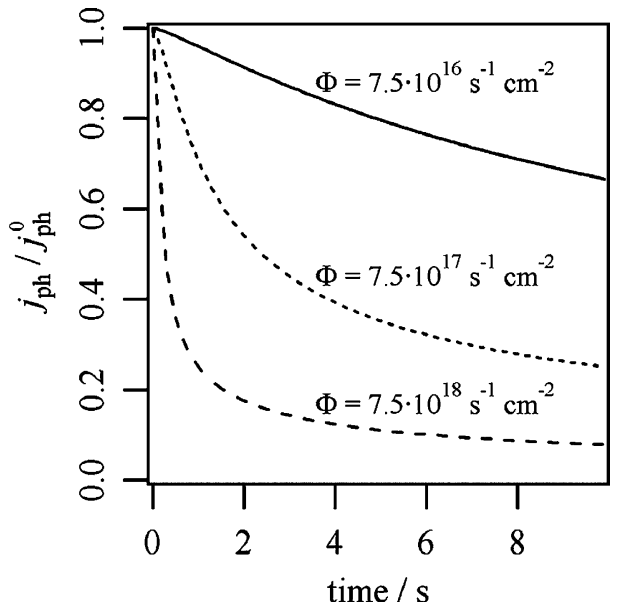

Fig. 9. Simulated normalised photocurrent transients for second order back charge transfer (model B) at various photon fluxes. Calculated from Eq. (32) with the parameters $g=10^{-10} \mathrm{~mol} \mathrm{~s}^{-1} \mathrm{~cm}^{-2}, c_{\mathrm{Q}}^{\mathrm{o}}=$ $10^{-3} \mathrm{~mol} \mathrm{dm}^{-3}, D_{\mathrm{Q}^{+}}^{\mathrm{o}}=D_{\mathrm{S}^{-}}^{\mathrm{W}}=10^{-5} \mathrm{~cm}^{2} \mathrm{~s}^{-1}$ and $k_{\mathrm{b}}^{\mathrm{II}}=5 \mathrm{dm}^{3} \mathrm{~mol}^{-1} \mathrm{~s}^{-1}$.

that vary from that of the reactants. In particular, the charged product in the organic phase is expected to be more hydrophilic than the corresponding neutral quencher. For instance, the formal ion transfer potential of ferricenium $\left(\mathrm{Fc}^{+}\right)$is about $0.005 \mathrm{~V}$, which falls within the potential window used in photocurrent experiments [26]. In the following model we will investigate the effect of coupled ion transfer on the photocurrent responses. The reaction scheme considered is that of model A with the addition of Eq. (35). The kinetics of the ion transfer reaction are based on the assumption of an activated ion transfer event [43]. The rate constants $k_{\mathrm{o}}$ and $k_{\mathrm{w}}$ relate to the transfer of $\mathrm{Q}^{+}$from the organic phase to water and from water to the organic phase, respectively.

Coupled ion transfer:

$\mathrm{Q}_{\mathrm{o}}^{+}+\mathrm{S}_{\mathrm{w}}^{-} \underset{k_{\mathrm{w}}}{\stackrel{k_{\mathrm{o}}}{\rightleftarrows}} \mathrm{Q}_{\mathrm{w}}^{+}+\mathrm{S}_{\mathrm{w}}^{-}$

The rate of ion transfer across the interface can be defined as

$v_{\text {ion }}=k_{\mathrm{o}} c_{\mathrm{Q}^{+}}^{\mathrm{o}}(0, t)-k_{\mathrm{w}} c_{\mathrm{Q}^{+}}^{\mathrm{w}}(0, t)$.

The photocurrent in the case of model $\mathrm{C}$ is given by

$j_{\mathrm{ph}}=F\left(v_{\mathrm{et}}-v_{\mathrm{b}}-v_{\text {ion }}\right)+\frac{\mathrm{d} q^{\mathrm{w}}}{\mathrm{d} t}$

The expression for the Laplace transform of the photocurrent according to model $\mathrm{C}$ is derived in Appendix C,

$\overline{\Delta j_{\mathrm{ph}}}=\frac{F g}{s} \frac{s+k_{\mathrm{ps}}-\frac{k_{\mathrm{p}} \lambda_{\mathrm{ion}}^{\mathrm{O}}}{s^{\frac{1}{2}}+\lambda_{\mathrm{ino}}^{\mathrm{w}}+\lambda_{\mathrm{ion}}^{\mathrm{o}}}}{\left(s+k_{\mathrm{ps}}+k_{\mathrm{b}}\right)+\lambda_{\mathrm{et}}\left(s+k_{\mathrm{ps}}\right) s^{-\frac{1}{2}}}$,

where $g$ and $\lambda_{\text {et }}$ are given by Eqs. (18) and (19), and $\lambda_{\text {ion }}^{\mathrm{W}}, \lambda_{\text {ion }}^{\mathrm{o}}$ correspond to $\lambda_{\text {ion }}^{\mathrm{o}}=\frac{k_{\mathrm{o}}}{D_{\mathrm{Q}^{+}}^{o^{\frac{1}{2}}}}$

and

$\lambda_{\text {ion }}^{\mathrm{w}}=\frac{k_{\mathrm{w}}}{D_{\mathrm{Q}^{+}}^{w^{2}}}$.

Again, there is no analytical expression for Eq. (38) in the time domain and the Stehfest algorithm has to be used to obtain inverse transformation numerically. Fig. 10(a) shows the effect of the rate constant of ion transfer of the photoproduct $\mathrm{Q}^{+}$on the photocurrent response. Only the forward ion transfer (from the organic medium to water) was considered in this case. The coupled ion transfer reaction introduces a non-exponential decay of the photocurrent on a time scale determined by the rate constants $k_{\mathrm{o}}$ and $k_{\mathrm{ps}}$ Despite the rather slow ion transfer rate constants used in these simulations, the coupled ion transfer has a substantial effect on the photocurrent
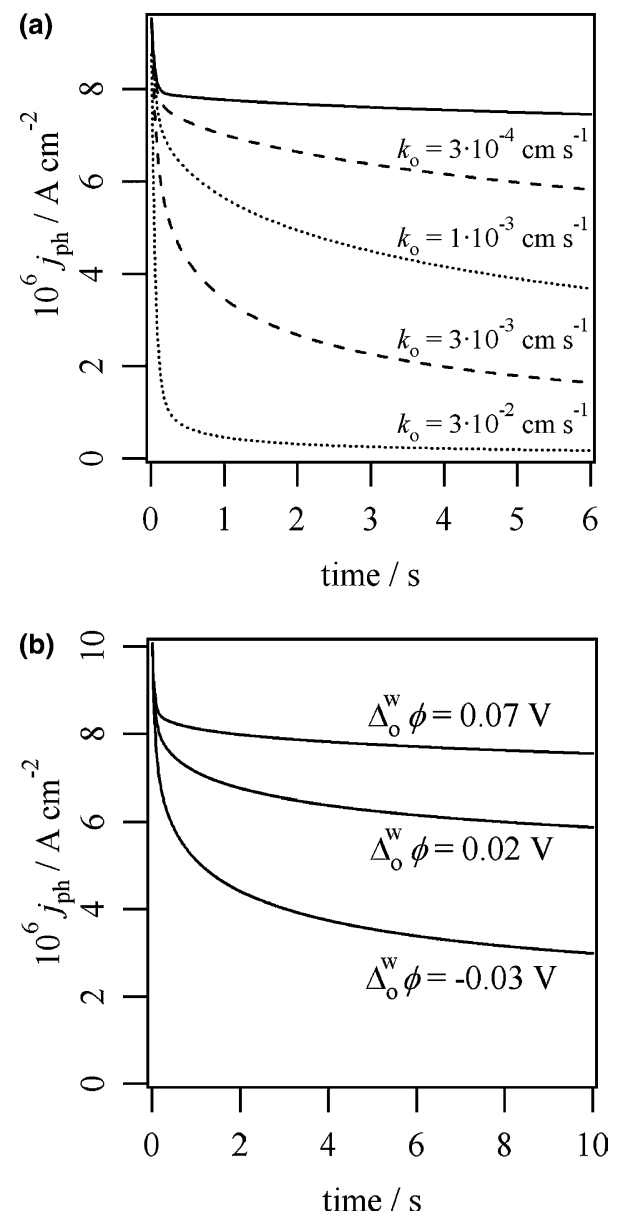

Fig. 10. Simulated photocurrent transients with coupled ion transfer (model C). Calculated from Eq. (38) employing the following parameters: $g=10^{-10} \mathrm{~mol} \mathrm{~s}^{-1} \mathrm{~cm}^{-2}, k_{\mathrm{ps}}=20 \mathrm{~s}^{-1}, k_{\mathrm{b}}=4 \mathrm{~s}^{-1}, c_{\mathrm{Q}}^{\mathrm{o}}=$ $10^{-3} \mathrm{~mol} \mathrm{dm}^{-3}, D_{\mathrm{Q}}^{\mathrm{o}}=D_{\mathrm{Q}^{+}}^{\mathrm{o}}=D_{\mathrm{Q}^{+}}^{\mathrm{w}}=10^{-5} \mathrm{~cm}^{-2} \mathrm{~s}^{-1}$ and (a) $k_{\mathrm{w}}=0$ and $k_{\mathrm{o}}$ as indicated in the graph; (b) $k_{\mathrm{o}}$ and $k_{\mathrm{w}}$ calculated from Eqs. (41) and (42) with $\Delta_{\mathrm{o}}^{\mathrm{w}} \phi_{\mathrm{Q}^{+}}^{\mathrm{o}^{\prime}}=0.005 \mathrm{~V}, k^{\circ}=10^{-3} \mathrm{~cm} \mathrm{~s}^{-1}$ and $\alpha=0.5$. 
response. The rates $k_{\mathrm{o}}$ and $k_{\mathrm{w}}$ are related to the standard rate constant $k^{\circ}$ of the ion transfer process by

$k_{\mathrm{w}}=k^{\circ} \exp \left(\frac{F \alpha\left(\Delta_{\mathrm{o}}^{\mathrm{w}} \phi-\Delta_{\mathrm{o}}^{\mathrm{w}} \phi_{\mathrm{Q}^{+}}^{\mathrm{o}^{\prime}}\right)}{R T}\right)$,

$k_{\mathrm{o}}=k^{\circ} \exp \left(-\frac{F(1-\alpha)\left(\Delta_{\mathrm{o}}^{\mathrm{w}} \phi-\Delta_{\mathrm{o}}^{\mathrm{w}} \phi_{\mathrm{Q}^{+}}^{\mathrm{o}^{\prime}}\right)}{R T}\right)$.

The decay introduced by the coupled partitioning of $\mathrm{Q}^{+}$ is attenuated when the ion transfer from water to the organic phase is considered. Fig. 10(b) illustrates the effect of the Galvani potential difference on the photocurrent response, taking $k_{\mathrm{et}}^{\mathrm{II}}$ as a constant and $\Delta_{\mathrm{o}}^{\mathrm{W}} \phi_{\mathrm{Q}^{+}}^{\mathrm{o}^{\prime}}=$ $0.005 \mathrm{~V}$ as in the case of ferrocene.

The photocurrent relaxation associated with the coupled ion transfer is affected by the photon flux, as shown in Fig. 11. In principle, the analysis of the light intensity dependence of the photocurrent decay can be taken as a diagnostic criterion for the elucidation of the photoinduced process. However, a large range of illumination levels is required, depending on the kinetics of the ion transfer reaction. The dynamics of coupled ion transfer have no effect on the initial value of the photocurrent, previously taken as proportional to the flux of electron injection [26,27], and only the subsequent relaxation of the photoresponse is affected. A similar conclusion has been reached based on the low electron injection limit [27].

\subsection{Comparison with experimental photocurrent transients}

Fig. 12(a) displays experimental photocurrent transients in the presence of the ZnTPPS-ZnTMPyP hetero-

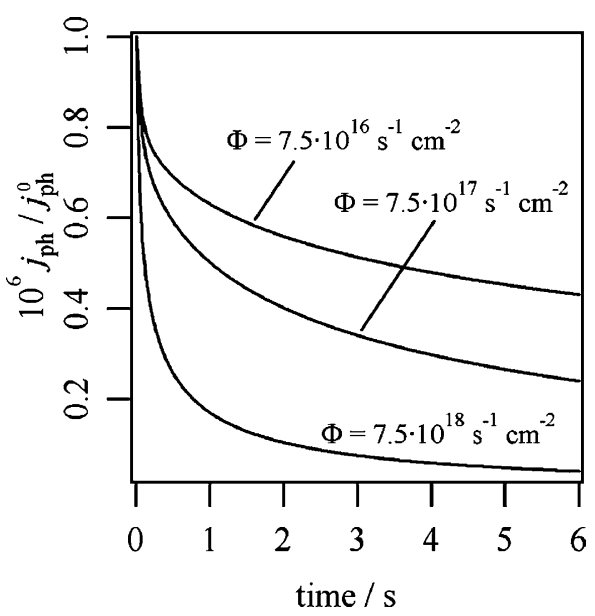

Fig. 11. Simulated normalised photocurrent transients in the presence of coupled ion transfer for various photon fluxes (model C). Calculated from Eq. (38) employing the parameters $g / \Phi=1.3 \times 10^{-26} \mathrm{~mol}$, $k_{\mathrm{ps}}=20 \mathrm{~s}^{-1}, \quad k_{\mathrm{b}}=4 \mathrm{~s}^{-1}, \quad c_{\mathrm{Q}}^{\mathrm{o}}=10^{-3} \mathrm{~mol} \mathrm{dm}^{-3}, D_{\mathrm{Q}}^{\mathrm{o}}=D_{\mathrm{Q}^{+}}^{\mathrm{o}}=D_{\mathrm{Q}^{+}}^{\mathrm{w}}=$ $10^{-5} \mathrm{~cm}^{-2} \mathrm{~s}^{-1}$ and photon fluxes as indicated in the graph.
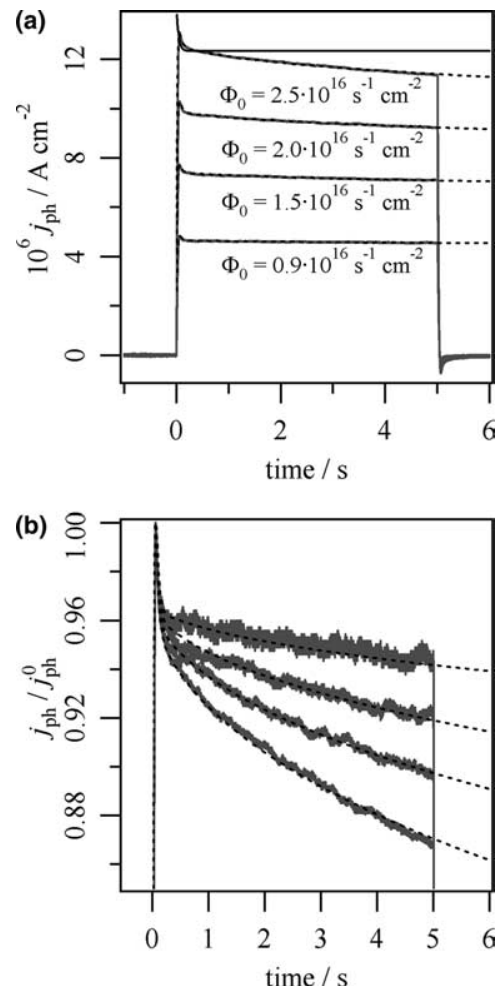

Fig. 12. Photocurrent responses in the presence of $\mathrm{Me}_{10} \mathrm{Fc}$ $10^{-3} \mathrm{~mol} \mathrm{dm}^{-3}$ in the DCE phase and ZnTMPyP $5 \times 10^{-5} \mathrm{~mol} \mathrm{dm}^{-3}$ and ZnTPPS $5 \times 10^{-5} \mathrm{~mol} \mathrm{dm}^{-3}$ in the aqueous phase. $\Delta_{\mathrm{o}}^{\mathrm{w}} \phi=0.007 \mathrm{~V}$. Dotted lines are simulations employing Eq. (21) with the parameters g/ $\Phi=6.3 \times 10^{-27} \mathrm{~mol}, \quad k_{\mathrm{ps}}=22 \mathrm{~s}^{-1}, \quad k_{\mathrm{b}}=4 \mathrm{~s}^{-1}, \quad D_{\mathrm{Q}}^{\mathrm{o}}=10^{-5}-2 \times$ $10^{-5} \mathrm{~cm}^{2} \mathrm{~s}^{-1}, R C=0.015 \mathrm{~s}^{-1}$ and photon fluxes at $442 \mathrm{~nm}$ as indicated in (a). The black line is a simulation employing Eq. (24) with the parameters corresponding to the highest photon flux. The photocurrents are normalised in (b) to illustrate the increase of diffusion effects at high photon fluxes. The largest light intensities correspond to the faster photocurrent decays.

dimer and decamethylferrocene $\left(\mathrm{Me}_{10} \mathrm{Fc}\right)$ as a donor in the organic phase, using different light intensities. The cell composition is described in Fig. 4. Simulations employing Eq. (21) are shown as dotted lines. The model developed in Section 3.1.2 appears to describe the photocurrent responses in the presence of $\mathrm{Me}_{10} \mathrm{Fc}$ adequately. The same photocurrents are normalised in Fig. 12(b) to illustrate the effect of the diffusion of the quencher. The faster decays are observed at high photon fluxes. These results should be compared to the simplified model described by Eq. (24). The black line in Fig. 12(a) is a simulation employing the same kinetic parameters, but neglecting the effects of diffusion and $R C$ attenuation. In this case, the photocurrent response shows a clear deviation from Eq. (24) on the time scale displayed in the graph. Although the initial part of the photocurrent remains practically unchanged when diffusion effects are taken into account, the $R C$ attenuation decreases the initial photocurrent slightly, leading to underestimations of the bimolecular rate constant of electron transfer in [26]. The rather slow back charge 
transfer observed in the presence of ferrocene derivatives means that minimal errors (of the order of a few percent) are introduced, and the conclusions presented in [26] on the kinetics of electron transfer remain unchanged.

It should be noted that the diffusion coefficient of the quencher obtained from the data in Fig. 12 appears to increase from $10^{-5}$ to $2 \times 10^{-5} \mathrm{~cm}^{2} \mathrm{~s}^{-1}$ as the photon flux is increased. This systematic variation may come as a result of the photo-stationary condition for $\Gamma_{\mathrm{S}^{*}}$ as defined by Eq. (16). Rigorously, diffusion phenomena should be accounted for in the expression of $\Gamma_{\mathrm{S}^{*}}$ as follows:

$\Gamma_{\mathrm{S}^{*}}=\frac{\sigma_{\mathrm{S}} \Phi \Gamma_{\mathrm{S}}}{k_{\mathrm{et}}^{\mathrm{II}}\left(c_{\mathrm{Q}}^{\mathrm{o}}+\Delta c_{\mathrm{Q}}^{\mathrm{o}}(0, t)\right)+k_{\mathrm{d}}}$.

Since $\Delta c_{\mathrm{O}}^{\mathrm{o}}$ is negative, the depletion of quencher at the interface leads to an increase in the surface excess of ex-
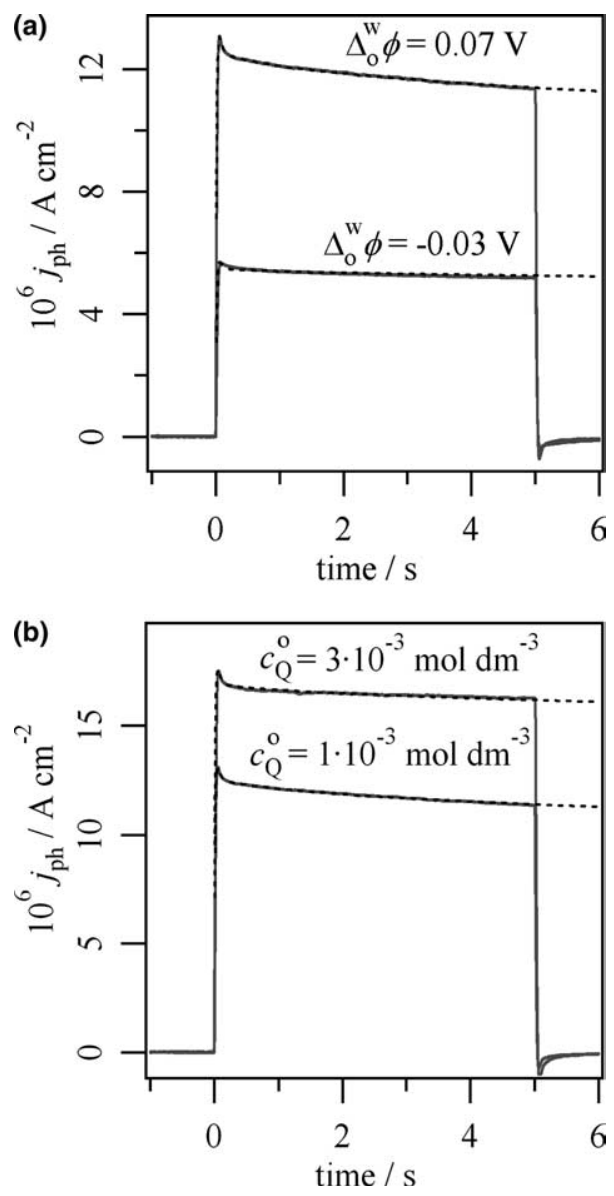

Fig. 13. Photocurrent responses in the presence of $\mathrm{Me}_{10} \mathrm{Fc}$ at various potentials (a) and concentrations (b) as indicated in the graph. Dotted lines are simulations employing Eq. (21) with the parameters $k_{\mathrm{ps}}=22 \mathrm{~s}^{-1}, k_{\mathrm{b}}=4 \mathrm{~s}^{-1}, D_{\mathrm{Q}}^{\mathrm{o}}=1.2 \times 10^{-5} \mathrm{~cm}^{2} \mathrm{~s}^{-1}, R C=0.015 \mathrm{~s}^{-1}$ and $g=1.6 \times 10^{-10} \mathrm{~mol} \mathrm{~s}^{-1} \mathrm{~cm}^{-2} \quad\left(\Delta_{\mathrm{o}}^{\mathrm{w}} \phi=0.07 \mathrm{~V}, c_{\mathrm{Q}}^{\mathrm{o}}=10^{-3} \mathrm{~mol} \mathrm{dm}^{-3}\right)$, $g=0.7 \times 10^{-10} \mathrm{~mol} \mathrm{~s}^{-1} \mathrm{~cm}^{-2} \quad\left(\Delta_{\mathrm{o}}^{\mathrm{w}} \phi=-0.03 \mathrm{~V}, c_{\mathrm{Q}}^{\mathrm{o}}=10^{-3} \mathrm{~mol} \mathrm{dm}^{-3}\right)$ or $g=2.1 \times 10^{-10} \mathrm{~mol} \mathrm{~s}^{-1} \mathrm{~cm}^{-2} \quad\left(\Delta_{\mathrm{o}}^{\mathrm{w}} \phi=0.07 \mathrm{~V}, c_{\mathrm{Q}}^{\mathrm{o}}=2.9 \times 10^{-3}\right.$ mol dm ${ }^{-3}$ ). The photon flux at $442 \mathrm{~nm}$ was $2.5 \times 10^{16} \mathrm{~cm}^{-2} \mathrm{~s}^{-1}$. cited-state porphyrins, thereby limiting the effect of diffusion on the transient response. However, Eq. (43) introduces mathematical complications that are beyond the scope of the present analysis.

As reported elsewhere, the changes observed in the photocurrent response upon tuning the potential difference between the two phases can be related to changes in the rate of electron transfer [26,27]. Fig. 13(a) shows the transient response obtained in the presence of decamethylferrocene $\left(\mathrm{Me}_{10} \mathrm{Fc}\right)$ at -0.03 and $0.07 \mathrm{~V}$. Simulations from Eq. (21) are superimposed on the experimental data. The changes in $g$ reflect the dependence of the pseudo-first order rate constant of electron $\operatorname{transfer}\left(k_{\mathrm{et}}=k_{\mathrm{et}}^{\mathrm{II}} c_{\mathrm{Q}}^{\mathrm{o}}\right)$ on the Galvani potential difference and concentration of quencher. The bulk concentration of quencher also affects the shape of the photocurrent transient response when diffusion phenomena are involved. Photocurrents in the presence of $10^{-3}$ and $3 \times 10^{-3} \mathrm{~mol} \mathrm{dm}^{-3} \mathrm{Me}_{10} \mathrm{Fc}$ at $\Delta_{\mathrm{o}}^{\mathrm{w}} \phi=0.07 \mathrm{~V}$ are displayed in Fig. 13(b). The simulations were obtained with parameters similar to those in Fig. 12.

With $\mathrm{Me}_{10} \mathrm{Fc}$ the back electron transfer reaction is slow in comparison to the product separation, and the photocurrent response appears practically in phase with the light perturbation. Fig. 14 shows the photocurrent responses associated with the oxidation of ferrocene $(\mathrm{Fc})$. In this case, the effect of the back electron transfer is much more pronounced, and the rate $k_{\mathrm{b}}$ increases strongly when the potential difference between the two phases is changed to more negative values. Comparison of the simulations in Fig. 10(b) with the experimental data in Fig. 14 suggests that the transfer of $\mathrm{Fc}^{+}$does

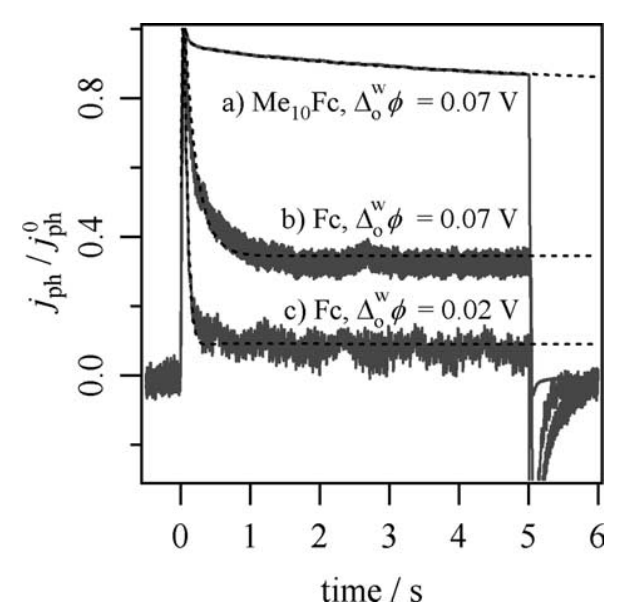

Fig. 14. Normalised photocurrent responses in the presence of $\mathrm{Me}_{10} \mathrm{Fc}$ or $\mathrm{Fc} 10^{-3} \mathrm{~mol} \mathrm{dm}^{-3}$ in the DCE phase and ZnTMPyP $5 \times 10^{-5} \mathrm{~mol} \mathrm{dm}^{-3}$ and ZnTPPS $5 \times 10^{-5} \mathrm{~mol} \mathrm{dm}^{-3}$ in the aqueous phase. Dotted lines are simulations employing Eq. (21) with the parameters $D_{\mathrm{Q}}^{\mathrm{o}}=1.2-1.4 \times 10^{-5} \mathrm{~cm}^{2} \mathrm{~s}^{-1}$ and (a) $g=1.6 \times 10^{-10}$ $\mathrm{mol} \mathrm{s} \mathrm{cm}^{-2}, \quad k_{\mathrm{ps}}=22 \mathrm{~s}^{-1}, \quad k_{\mathrm{b}}=4 \mathrm{~s}^{-1}, \quad R C=0.015 \mathrm{~s}^{-1}$; (b) $g=$ $0.11 \times 10^{-10} \mathrm{~mol} \mathrm{~s}^{-1} \mathrm{~cm}^{-2}, k_{\mathrm{ps}}=1.6 \mathrm{~s}^{-1}, k_{\mathrm{b}}=4 \mathrm{~s}^{-1}, R C=0.012 \mathrm{~s}^{-1}$; (c) $g=0.09 \times \quad 10^{-10} \mathrm{~mol} \mathrm{~s}^{-1} \mathrm{~cm}^{-2}, \quad k_{\mathrm{ps}}=1.0 \mathrm{~s}^{-1}, \quad k_{\mathrm{b}}=25 \mathrm{~s}^{-1}$, $R C=0.030 \mathrm{~s}^{-1}$. 
not significantly affect the photocurrent responses at potentials far from $\Delta_{\mathrm{o}}^{\mathrm{w}} \phi_{\mathrm{Fc}^{+}}^{\mathrm{o}^{\prime}}$. This effect is expected to be more pronounced at potentials closer to the formal ion transfer potential. However, the small magnitude of the photocurrent responses prevents a consistent analysis of these phenomena. Furthermore, the decays associated with back electron transfer and ion transfer reactions are difficult to decouple on the basis of transient measurements. A more sensitive technique such as IMPS should be used to investigate these responses. We also expect to employ this method to study the photoinduced reduction of quinone species. In this case the back charge transfer is not related to the ion transfer of the products, but to the heterogeneous protonation of the quinone radical anion. Assuming that the surface concentration of protons remains constant, this system is similar to that described by model $\mathrm{C}$ with a rate constant $k_{\mathrm{w}}$ equal to zero.

\section{Conclusions}

The photoinduced heterogeneous electron transfer reaction described by Fig. 2 has been rationalised in terms of a detailed model including the diffusion of species toward the interface. At low photon fluxes the effect of diffusion is negligible, and the expression for the current density across the interface simplifies to that of the phenomenological model presented in earlier publications [14,21,26,27]. At higher light intensities, the decay of the photocurrent can be effectively attributed to the depletion of the organic reactant at the interface (see Fig. 12). The solution of the diffusion problem allows rationalisation of the photocurrent dependence on the illumination over a wide range of light intensities. This theoretical framework also offers diagnostic criteria for elucidating the contribution of processes such as back charge transfer, diffusion effects and $R C$ attenuation to the photocurrent relaxation.

The simulations provided by model A adequately describe the photocurrent responses originating from the heterogeneous quenching of the ZnTPPS-ZnTMPyP heterodimer by ferrocene species. The consistency of the experimental curves with the present model confirms that the surface concentration of porphyrins remains constant over a wide range of experimental conditions. This assumption appears to be valid not only for low photon fluxes and short illumination periods, but also after constant illumination for hours. These results suggest that the porphyrins are regenerated at the interface after the heterogeneous photo-electrochemical step. The regeneration step does not contribute directly to the photocurrent response as no heterogeneous charge transfer is involved. The nature of this process is currently under investigation.
Second order back electron transfer (model B) and coupled ion transfer of the photoproducts (model C) were also considered. Second order back electron transfer manifests itself by a strong dependence of the photocurrent decay on the illumination intensity, which was not observed experimentally. On the other hand, coupled ion transfer reactions cannot be excluded. The partitioning of charged photoproducts introduces an additional decay component in the photocurrent response, depending on the rate constants associated with the ion transfer and product separation processes. The effects of back electron transfer and ion transfer are difficult to separate on the basis of photocurrent transients, and more sensitive techniques such as IMPS should be considered.

Finally, it should be mentioned that this model could be employed in a variety of dye sensitised polarisable interfaces. For instance, this model can be extended to solid electrodes modified by dye sensitised liquid films [44] or ultrathin polyelectrolyte multilayers [29].

\section{Acknowledgements}

This work has been supported by the Fonds National Suisse de la Recherche Scientifique (Project 2067050.01). Z.S. gratefully acknowledges a Visiting Fellowship from the EPFL and financial support from the Ministry of Education, Youth and Sports of the Czech Republic (Grant No. KONTAKT/ME 502).

\section{Appendix A. Boundary conditions and mathematical developments for model A}

The liquid|liquid interface is defined as a sharp boundary located at $x=0$. At this position the fluxes $J_{i}$ of the electroactive species in Fig. 2 fulfil the Eqs. (A.1)-(A.6)

$$
\begin{aligned}
& J_{\mathrm{Q}}^{\mathrm{o}}=-D_{\mathrm{Q}}^{\mathrm{o}}\left(\frac{\partial c_{\mathrm{Q}}^{\mathrm{o}}}{\partial x}\right)_{x=0}=-\left(v_{\mathrm{et}}-v_{\mathrm{b}}\right)-\frac{\mathrm{d} \Gamma_{\mathrm{Q}}^{\mathrm{o}}}{\mathrm{d} t}, \\
& J_{\mathrm{Q}^{+}}^{\mathrm{o}}=-D_{\mathrm{Q}^{+}}^{\mathrm{o}}\left(\frac{\partial c_{\mathrm{Q}^{+}}^{\mathrm{o}}}{\partial x}\right)_{x=0}=k_{\mathrm{ps}} \Gamma_{\mathrm{SQ}}-\frac{\mathrm{d} \Gamma_{\mathrm{Q}^{+}}^{\mathrm{o}}}{\mathrm{d} t}, \\
& J_{\mathrm{S}}^{\mathrm{w}}=-D_{\mathrm{S}}^{\mathrm{w}}\left(\frac{\partial c_{\mathrm{S}}^{\mathrm{w}}}{\partial x}\right)_{x=0}=k_{\mathrm{ads}} c_{\mathrm{S}}^{\mathrm{w}}(0, t)-k_{\mathrm{des}} \Gamma_{\mathrm{S}}, \\
& J_{\mathrm{S}^{-}}^{\mathrm{w}}=-D_{\mathrm{S}^{-}}^{\mathrm{w}}\left(\frac{\partial c_{\mathrm{S}^{-}}^{\mathrm{w}}}{\partial x}\right)_{x=0}=-k_{\mathrm{ps}} \Gamma_{\mathrm{SQ}}+\frac{\mathrm{d} \Gamma_{\mathrm{S}^{-}}^{\mathrm{w}}}{\mathrm{d} t}, \\
& J_{K}^{\mathrm{w}}=-D_{K}^{\mathrm{w}}\left(\frac{\partial c_{K}^{\mathrm{w}}}{\partial x}\right)_{x=0}=\frac{\mathrm{d} \Gamma_{K}^{\mathrm{w}}}{\mathrm{d} t}, \quad K=\left(\mathrm{R}^{+}, \mathrm{X}^{-}\right), \\
& J_{L}^{\mathrm{o}}=-D_{L}^{\mathrm{o}}\left(\frac{\partial c_{L}^{\mathrm{o}}}{\partial x}\right)_{x=0}=-\frac{\mathrm{d} \Gamma_{L}^{\mathrm{o}}}{\mathrm{d} t}, \quad L=\left(\mathrm{T}^{+}, \mathrm{Y}^{-}\right) .
\end{aligned}
$$


The specific adsorption of the species $\mathrm{Q}, \mathrm{Q}^{+}$and $\mathrm{S}^{-}$is neglected. One should note that in practice, $\mathrm{Li}_{2} \mathrm{SO}_{4}$ was used as a supporting electrolyte in the aqueous phase in most cases, instead of a monovalent salt of the form RX. However, this has little influence on the following development, and has been omitted for the sake of simplicity. In order to ensure that the boundary conditions in Eqs. (A.1)-(A.6) were consistently established, we must verify that the summation of the fluxes on the aqueous side of the interface yields expression (13). The surface charge density in the aqueous phase is obtained from the electroneutrality condition (Eq. (2)). The electric current density is described as follows:

$j_{\mathrm{ph}}=\sum_{i} z_{i} F J_{i}^{\mathrm{w}}=z_{\mathrm{S}} F J_{\mathrm{S}}^{\mathrm{w}}+z_{\mathrm{S}^{-}} F J_{\mathrm{S}^{-}}^{\mathrm{w}}+F \frac{\mathrm{d} \Gamma_{\mathrm{R}^{+}}^{\mathrm{w}}}{\mathrm{d} t}-F \frac{\mathrm{d} \Gamma_{\mathrm{X}^{-}}^{\mathrm{w}}}{\mathrm{d} t}$.

Substituting the fluxes $J_{\mathrm{S}}^{\mathrm{w}}$ and $J_{\mathrm{S}^{-}}^{\mathrm{w}}$ with the expressions (A.3) and (A.4), and using the electroneutrality condition (2) yields

$$
\begin{aligned}
j_{\mathrm{ph}}= & z_{\mathrm{S}} F\left(k_{\mathrm{ads}} c_{\mathrm{S}}^{\mathrm{w}}(0, t)-k_{\mathrm{des}} \Gamma_{\mathrm{S}}\right)-z_{\mathrm{S}^{-}} F k_{\mathrm{ps}} \Gamma_{\mathrm{SQ}^{+}} \\
& +\frac{\mathrm{d} q^{\mathrm{w}}}{\mathrm{d} t}-z_{\mathrm{S}} F \frac{\mathrm{d}\left(\Gamma_{\mathrm{S}}+\Gamma_{\mathrm{S}}^{*}\right)}{\mathrm{d} t}-z_{\mathrm{S}^{-}} F \frac{\mathrm{d} \Gamma_{\mathrm{SQ}}}{\mathrm{d} t} .
\end{aligned}
$$

Eq. (A.8) simplifies to expression (13) for the total current response of the cell upon illumination when the time derivatives of the surface concentrations are substituted with the corresponding kinetic equations ((8)-(10)). The Laplace transform of Eq. (13) reads

$\overline{\Delta j_{\mathrm{ph}}}=F\left(\overline{\Delta v_{\mathrm{et}}}-\overline{\Delta v_{\mathrm{b}}}\right)+s \overline{\Delta q^{\mathrm{w}}}$

and that of the equation of the flux of $\mathrm{Q}$ on the aqueous side of the interface (Eq. (A.1)) yields

$\left(s D_{\mathrm{Q}}^{\mathrm{o}}\right)^{\frac{1}{2}} \overline{\Delta c_{\mathrm{Q}}^{\mathrm{o}}}=-\left(\overline{\Delta v_{\mathrm{et}}}-\overline{\Delta v_{\mathrm{b}}}\right)$.

The Laplace transforms of the expressions for the rates of electron transfer read

$\overline{\Delta v_{\mathrm{et}}}=k_{\mathrm{et}}^{\mathrm{II}} c_{\mathrm{Q}}^{\mathrm{o}} \overline{\Delta \Gamma_{\mathrm{S}^{*}}}+k_{\mathrm{et}}^{\mathrm{II}} \Gamma_{\mathrm{S}^{*}}^{0} \overline{\Delta c_{\mathrm{Q}}^{\mathrm{o}}}$,

$\overline{\Delta v_{\mathrm{b}}}=k_{\mathrm{b}} \overline{\Delta \Gamma_{\mathrm{SQ}}}$.

And the Laplace transform of Eq. (10) is

$\overline{\Delta \Gamma_{\mathrm{SQ}}}=\frac{\overline{\Delta v_{\mathrm{et}}}}{s+k_{\mathrm{ps}}+k_{\mathrm{b}}}$.

Combining Eqs. (A.9)-(A.13), one obtains Eq. (17) describing the photocurrent in the Laplace plane.

\section{Appendix B. Boundary conditions and mathematical developments for model B}

The boundary conditions in the case of model B are slightly different from model A. In addition to Eq.
(A.3) for the adsorbed dye in the ground state, the fluxes associated with this reaction are

$$
\begin{aligned}
& J_{\mathrm{Q}}^{\mathrm{o}}=-D_{\mathrm{Q}}^{\mathrm{o}}\left(\frac{\partial c_{\mathrm{Q}}^{\mathrm{o}}}{\partial x}\right)_{x=0}=-\left(v_{\mathrm{et}}-v_{\mathrm{b} 2}\right)-\frac{\mathrm{d} \Gamma_{\mathrm{Q}}^{\mathrm{o}}}{\mathrm{d} t}, \\
& J_{\mathrm{Q}^{+}}^{\mathrm{o}}=-D_{\mathrm{Q}^{+}}^{\mathrm{o}}\left(\frac{\partial c_{\mathrm{Q}^{+}}^{\mathrm{o}}}{\partial x}\right)_{x=0}=\left(v_{\mathrm{et}}-v_{\mathrm{b} 2}\right)-\frac{\mathrm{d} \Gamma_{\mathrm{Q}^{+}}^{\mathrm{o}}}{\mathrm{d} t}, \\
& J_{\mathrm{S}^{-}}^{\mathrm{w}}=-D_{\mathrm{S}^{-}}^{\mathrm{w}}\left(\frac{\partial c_{\mathrm{S}^{-}}^{\mathrm{w}}}{\partial x}\right)_{x=0}=-\left(v_{\mathrm{et}}-v_{\mathrm{b} 2}\right) .
\end{aligned}
$$

The photocurrent in the case of model B (Eq. (31)) can be expressed from Eqs. (B.1)-(B.3), neglecting the effect of double layer charging:

$$
\begin{aligned}
\overline{\Delta j_{\mathrm{ph}}} & =-F\left(s D_{\mathrm{Q}}^{\mathrm{o}}\right)^{\frac{1}{2}} \overline{\Delta c_{\mathrm{Q}}^{\mathrm{o}}}=F\left(s D_{\mathrm{S}^{-}}^{\mathrm{W}}\right)^{\frac{1}{2}} \overline{\Delta c_{\mathrm{S}^{-}}^{\mathrm{W}}} \\
& =F\left(s D_{\mathrm{Q}^{+}}^{\mathrm{o}}\right)^{\frac{1}{2}} \overline{\Delta c_{\mathrm{Q}^{+}}^{\mathrm{o}}} .
\end{aligned}
$$

The inverse Laplace transform of Eq. (B.4) yields

$c_{\mathrm{S}^{-}}^{\mathrm{w}}(0, t)=\Delta c_{\mathrm{S}^{-}}^{\mathrm{w}}=-\left(\frac{D_{\mathrm{Q}}^{\mathrm{o}}}{D_{\mathrm{S}^{-}}^{\mathrm{w}}}\right)^{\frac{1}{2}} \Delta c_{\mathrm{Q}^{\mathrm{o}}}^{\mathrm{o}}$.

The concentration of oxidised quencher in the vicinity of the interface is simply expressed by

$c_{\mathrm{Q}^{+}}^{\mathrm{o}}(0, t)=c_{\mathrm{Q}}^{\mathrm{o}}-c_{\mathrm{Q}}^{\mathrm{o}}(0, t)=-\Delta c_{\mathrm{Q}}^{\mathrm{o}}$.

From these equations the photocurrent can be related to the variations in concentration by the convolution integral in Eq. (34).

\section{Appendix C. Boundary conditions and mathematical developments for model $\mathrm{C}$}

The fluxes corresponding to the reaction scheme in model $\mathrm{C}$ are described by Eqs. (A.1)-(A.6), with the exception of

$$
\begin{aligned}
& J_{\mathrm{Q}^{+}}^{\mathrm{o}}=-D_{\mathrm{Q}^{+}}^{\mathrm{o}}\left(\frac{\partial c_{\mathrm{Q}^{+}}^{\mathrm{o}}}{\partial x}\right)_{x=0}=k_{\mathrm{ps}} \Gamma_{\mathrm{SQ}}-v_{\text {ion }}-\frac{\mathrm{d} \Gamma_{\mathrm{Q}^{+}}^{\mathrm{o}}}{\mathrm{d} t}, \\
& J_{\mathrm{Q}^{+}}^{\mathrm{w}}=-D_{\mathrm{Q}^{+}}^{\mathrm{w}}\left(\frac{\partial c_{\mathrm{Q}^{+}}^{\mathrm{w}}}{\partial x}\right)_{x=0}=-v_{\text {ion }}+\frac{\mathrm{d} \Gamma_{\mathrm{Q}^{+}}^{\mathrm{w}}}{\mathrm{d} t} .
\end{aligned}
$$

The Laplace transform of the photocurrent in the case of model C (Eq. (37)) reads:

$\overline{\Delta j_{\mathrm{ph}}}=F\left(\overline{\Delta v_{\mathrm{et}}}-\overline{\Delta v_{\mathrm{b}}}-\overline{\Delta v_{\text {ion }}}\right)+s \overline{\Delta q^{\mathrm{w}}}$.

As in the case of model $\mathrm{A}$, the following expression is obtained when the effects of double layer charging are neglected:

$\overline{\Delta v_{\mathrm{et}}}=\frac{g}{s} \frac{s+k_{\mathrm{ps}}+k_{\mathrm{b}}}{\left(s+k_{\mathrm{ps}}+k_{\mathrm{b}}\right)+\lambda_{\mathrm{et}}\left(s+k_{\mathrm{ps}}\right) s^{-\frac{1}{2}}}$, 
where the parameters $g, \lambda_{\mathrm{et}}$ and $\overline{\Delta v_{\mathrm{b}}}$ are given by Eqs. (18), (19) and (A.12). The Laplace transforms of Eqs. (C.1) and (C.2) read

$$
\begin{aligned}
& \left(s D_{\mathrm{Q}^{+}}^{\mathrm{o}}\right)^{\frac{1}{2}} \overline{\Delta c_{\mathrm{Q}^{+}}^{\mathrm{o}}}=k_{\mathrm{ps}} \overline{\Delta \Gamma_{\mathrm{SQ}}}-\overline{\Delta v_{\text {ion }}}, \\
& -\left(s D_{\mathrm{Q}^{+}}^{\mathrm{w}}\right)^{\frac{1}{2}} \overline{\Delta c_{\mathrm{Q}^{+}}^{\mathrm{W}}}=-\overline{\Delta v_{\text {ion }}} .
\end{aligned}
$$

Combining these equations with Eqs. (A.13) and (36) we obtain

$$
\begin{aligned}
& \overline{\Delta c_{\mathrm{Q}^{+}}^{\mathrm{W}}}=\frac{k_{\mathrm{o}} \overline{\Delta c_{\mathrm{Q}^{+}}^{\mathrm{o}}}}{\left(s D_{\mathrm{Q}^{+}}^{\mathrm{w}}\right)^{\frac{1}{2}}+k_{\mathrm{w}}}, \quad(\mathrm{C} .7) \\
& \overline{\Delta c_{\mathrm{Q}^{+}}^{\mathrm{o}}}=\left(\frac{k_{\mathrm{ps}} \overline{\Delta v_{\mathrm{et}}}}{s+k_{\mathrm{ps}}+k_{\mathrm{b}}}\right) \frac{\left(s D_{\mathrm{Q}^{+}}^{\mathrm{w}}\right)^{\frac{1}{2}}+k_{\mathrm{w}}}{\left(D_{\mathrm{Q}^{+}}^{\mathrm{o}} D_{\mathrm{Q}^{+}}^{\mathrm{w}}\right)^{\frac{1}{2}}+k_{\mathrm{w}}\left(s D_{\mathrm{Q}^{+}}^{\mathrm{o}}\right)^{\frac{1}{2}}+k_{\mathrm{o}}\left(s D_{\mathrm{Q}^{+}}^{\mathrm{w}}\right)^{\frac{1}{2}}}
\end{aligned}
$$

and finally

$\overline{\Delta v_{\text {ion }}}=\left(\frac{k_{\mathrm{ps}} \overline{\Delta v_{\mathrm{et}}}}{s+k_{\mathrm{ps}}+k_{\mathrm{b}}}\right) \frac{\lambda_{\text {ion }}^{\mathrm{o}}}{s^{\frac{1}{2}}+\lambda_{\text {ion }}^{\mathrm{w}}+\lambda_{\text {ion }}^{\mathrm{o}}}$,

where $\lambda_{\text {ion }}^{\mathrm{o}}=k_{\mathrm{o}} /\left(D_{\mathrm{Q}^{+}}^{\mathrm{o}}\right)^{\frac{1}{2}}$ and $\lambda_{\text {ion }}^{\mathrm{w}}=k_{\mathrm{w}} /\left(D_{\mathrm{Q}^{+}}^{\mathrm{w}}\right)^{\frac{1}{2}}$ (Eqs. (39) and (40)). Substitution of the terms $\overline{\Delta v_{\mathrm{et}}}, \overline{\Delta v_{\mathrm{b}}}$ and $\overline{\Delta v_{\text {ion }}}$ in Eq. (C.3) yields Eq. (38) for the photocurrent in the Laplace plane, neglecting the charging of the double layer.

\section{Appendix D. Stehfest method for numerical inversion of Laplace transforms}

The method developed by Stehfest [41] can be used for numerical simulation of the photocurrent transients. If $F(s)$ is the function in the Laplace plane, the original function $f(t)$ can be approximated by

$f(t)=\frac{\ln (2)}{t} \sum_{i=1}^{N} V_{i} F\left(\frac{\ln (2)}{t} \mathrm{i}\right)$

where the quantity $\frac{\ln (2)}{t} \mathrm{i}$ substitutes for the Laplace variable $s$. The coefficients $V_{i}$ are given by

$V_{i}=(-1)^{\frac{N}{2}+1} \sum_{k=\left[\frac{i+1}{2}\right]}^{\min \left(i, \frac{N}{2}\right)} \frac{k^{\frac{N}{2}}(2 k) !}{\left(\frac{N}{2}-k\right) ! k !(k-1) !(2 k-1) !}$,

where $N$ is an even number and $k$ is computed using integer arithmetic. The value of $N$ was chosen as 10 in all simulations. In principle, large values of $N$ increase the accuracy of the numerically inverted solution. In practice, however, $N$ is limited by truncation errors, and a large number of iterations leads to instabilities in the solution [42]. The Stehfest algorithm was tested on the simplified equation (24), and very good correlation was observed between the numerical and analytical inversions.

\section{References}

[1] A.G. Volkov, D.W. Deamer, Liquid-Liquid Interfaces: Theory and Methods, CRC Press, Boca Raton, FL, 1996.

[2] A.G. Volkov, D.W. Deamer, D.I. Tanelian, V.S. Markin, Liquid Interfaces in Chemistry and Biology, Wiley, New York, 1998.

[3] K. Kalyanasundaram, Photochemistry of Microheterogeneous Systems, Academic Press, London, 1987.

[4] J.N. Robinson, D.J. Cole-Hamilton, Chem. Soc. Rev. 20 (1991) 49.

[5] N.A. Kotov, M.G. Kuzmin, J. Electroanal. Chem. 285 (1990) 223.

[6] N.A. Kotov, M.G. Kuzmin, J. Electroanal. Chem. 341 (1992) 47.

[7] N.A. Kotov, M.G. Kuzmin, J. Electroanal. Chem. 338 (1992) 99.

[8] V. Marecek, A.H. De Armond, M.K. De Armond, J. Am. Chem. Soc. 111 (1989) 2561.

[9] D.J. Fermín, R. Lahtinen, in: A.G. Volkov (Ed.), Liquid Interfaces in Chemical, Biological and Pharmaceutical Applications, Marcel Dekker, New York, 2001, p. 179.

[10] A.R. Brown, L.J. Yellowlees, H.H. Girault, J. Chem. Soc., Faraday Trans. 89 (1993) 207.

[11] F.L. Thomson, L.J. Yellowlees, H.H. Girault, J. Chem. Soc., Chem. Commun. (1988) 1547.

[12] D.J. Fermín, Z. Ding, H.D. Duong, P.F. Brevet, H.H. Girault, J. Phys. Chem. B 102 (1998) 10334.

[13] D.J. Fermín, Z. Ding, H.D. Duong, P.F. Brevet, H.H. Girault, Chem. Commun. (1998) 1125.

[14] D.J. Fermín, H.D. Duong, Z. Ding, P.F. Brevet, H.H. Girault, Phys. Chem. Chem. Phys. 1 (1999) 1461.

[15] Z. Ding, Ph.D. Thesis, EPFL, 1999.

[16] K.L. Kott, D.A. Higgins, R.J. McMahon, R.M. Corn, J. Am. Chem. Soc. 115 (1993) 5342.

[17] R.A.W. Dryfe, Z. Ding, R.G. Wellington, P.F. Brevet, A.M. Kuznetzov, H.H. Girault, J. Phys. Chem. A 101 (1997) 2519.

[18] H.D. Duong, P.F. Brevet, H.H. Girault, J. Photochem. Photobiol. 117 (1998) 27.

[19] A. Piron, Ph.D. Thesis, EPFL, 2001.

[20] N. Eugster, Ph.D. Thesis, EPFL, 2004.

[21] D.J. Fermín, H.D. Duong, Z. Ding, P.F. Brevet, H.H. Girault, J. Am. Chem. Soc. 121 (1999) 10203.

[22] D.J. Fermín, H.D. Duong, Z. Ding, P.F. Brevet, H.H. Girault, Electrochem. Commun. 1 (1999) 29.

[23] R.M. Lahtinen, D.J. Fermín, K. Kontturi, H.H. Girault, J. Electroanal. Chem. 483 (2000) 81.

[24] H. Jensen, J.J. Kakkassery, H. Nagatani, D.J. Fermín, H.H. Girault, J. Am. Chem. Soc. 122 (2000) 10943.

[25] H. Jensen, D.J. Fermín, H.H. Girault, Phys. Chem. Chem. Phys. 3 (2001) 2503.

[26] N. Eugster, D.J. Fermín, H.H. Girault, J. Phys. Chem. B 106 (2002) 3428.

[27] N. Eugster, D.J. Fermín, H.H. Girault, J. Am. Chem. Soc. 125 (2003) 4862.

[28] F. Reymond, D.J. Fermín, H.J. Lee, H.H. Girault, Electrochim. Acta 45 (2000) 2647.

[29] J.J. Kakkassery, D.J. Fermín, H.H. Girault, Chem. Commun. (2002) 1240.

[30] H. Nagatani, A. Piron, P.F. Brevet, D.J. Fermín, H.H. Girault, Langmuir 18 (2002) 6647.

[31] H. Nagatani, Z. Samec, P.F. Brevet, D.J. Fermín, H.H. Girault, J. Phys. Chem. B 107 (2003) 786. 
[32] N. Eugster, H. Jensen, D.J. Fermin, H.H. Girault, J. Electroanal. Chem. 560 (2003) 143.

[33] M. Hugerat, H. Levanon, E. Ojadi, L. Biczok, H. Linschitz, Chem. Phys. Lett. 181 (1991) 400.

[34] D.-M. Chen, Y.-H. Zhang, T.-J. He, F.-C. Liu, Spectrochim. Acta A 58 (2002) 2291.

[35] H. van Willigen, U. Das, E. Ojadi, H. Linschitz, J. Am. Chem. Soc. 107 (1985) 7784.

[36] U. Hofstra, R.B.M. Koehorst, T.J. Schaafsma, Chem. Phys. Lett 130 (1986) 555.

[37] F.J. Vergeldt, R.B.M. Koehorst, T.J. Schaafsma, J.C. Lambry, J.L. Martin, D.G. Johnson, M.R. Wasiliewski, Chem. Phys. Lett. 182 (1991) 107.
[38] See the web site lepa.epfl.ch for a comprehensive list of Gibbs energies of ion transfer at various liquid|liquid interfaces.

[39] H. Nagatani, D.J. Fermin, H.H. Girault, J. Phys. Chem. B 105 (2001) 9463.

[40] L.M. Peter, Chem. Rev. 90 (1990) 753.

[41] H. Stehfest, Commun. Assoc. Comput. Mach. 13 (1970) 47.

[42] A.F. Moench, A. Ogata, Water Resour. Res. 17 (1981) 250.

[43] D.J. Fermín, H. Jensen, H.H. Girault, in: E.J. Calvo (Ed.), Encyclopedia of Electrochemistry, Interfacial Kinetics and Mass Transport, vol. 2, Wiley-VCH, New York, 2003, p. 360.

[44] S. Ulmeanu, H.J. Lee, D.J. Fermín, H.H. Girault, Y. Shao, Electrochem. Commun. 3 (2001) 219. 